
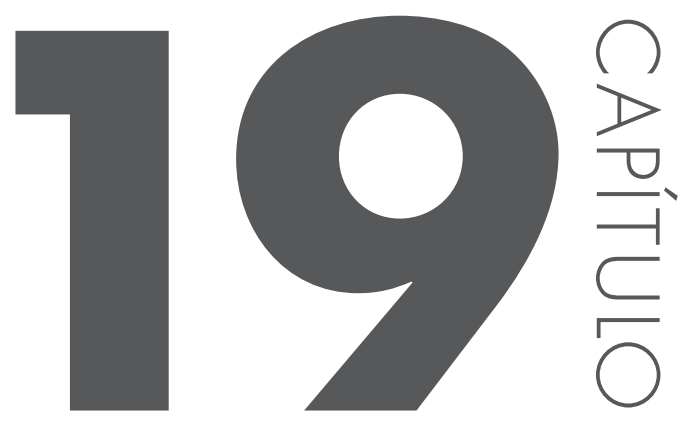

\title{
FISIOLOGIA DAS SECREC̣ÕES SALIVARES E GASTRINTESTINAIS
}

Vilma Lima

Iracema Matos Melo

Vilana Maria Adriano Araújo

Jairo Diniz Filho

\subsection{INTRODUC̣ÃO}

A função do sistema digestório consiste em prover nutrientes para o corpo enquanto o alimento transita pelo tubo digestivo desde a boca, seguindo pelo esôfago, o estômago e os intestinos, antes de ser esvaziado. $\mathrm{O}$ trato gas- 
trointestinal realiza a digestão dos alimentos, porém não digere a si mesmo. Abriga grande quantidade de bactérias, mais que o próprio número de células do corpo humano, sendo que o ácido clorídrico gástrico, bem como o muco, previnem a multiplicação anormal da microbiota e acúmulo de seus produtos, prevenindo danos aos órgãos. Os mecanismos por trás dessas habilidades variam, mas uma das principais razões refere-se às suas secreções glandulares (Johansson et al., 2013).

Assim, as glândulas secretoras desempenham duas funções primárias: a secretora, com a produção de enzimas e muco, e a função de proteção do tubo digestivo. As secreções das glândulas do trato gastrintestinal e órgãos associados ocorrem em resposta aos alimentos que trafegam ao longo do tubo digestivo, tornando-os, portanto, passíveis de serem absorvidos. Desse modo, para cada tipo de secreção é importante compreender sua composição e sua função no organismo, além de sua formação e seu controle (Fry, 2009).

Existem vários tipos de secreções do trato gastrointestinal, como as relacionadas com mecanismos neuroendócrinos, endócrinos e exócrinos. A primeira envolve neurotransmissores e/ou neuromoduladores; a endócrina, envolvendo hormônios, enquanto a última envolve mucosa, serosa e/ou hidroeletrólitos (Lee et al., 2012). As secreções mais importantes são as salivar, gástrica, pancreática, hepática e as do intestino delgado. A secreção salivar é constituída por grandes quantidades de muco e, também, enzimas como a ptialina, uma enzima que inicia a digestão de compostos amiláceos. A secreção gástrica é formada por grande quantidade de ácido clorídrico e da enzima pepsina, ambos muito importantes para o início da digestão de proteínas. O pâncreas contribui com grandes quantidades de tripsina, utilizada para a continuação da digestão de proteínas, além de amilase e lipase pancreáticas, para a digestão de carboidratos e gorduras, respectivamente. Ainda, a secreção pancreática contém concentrações elevadas de bicarbonato de sódio, necessário para a neutralização de ácidos que chegam ao duodeno, provenientes do estômago. Já o fígado, contribui para a digestão com a secreção de bile, rica em sais biliares, o que favorece a emulsificação das gorduras. As secreções do intestino delgado contém altos teores de muco, água e eletrólitos, não obstante suas células epiteliais que recobrem as vilosidades contém peptidases, para a etapa final da digestão das proteínas, além de sucrase, lactase e maltase, para a finalização da digestão de carboidratos, e ainda, pequena quantidade de lipase intestinal, útil para a digestão de gorduras (Guyton; Hall, 2011) (Figura 19.1). 


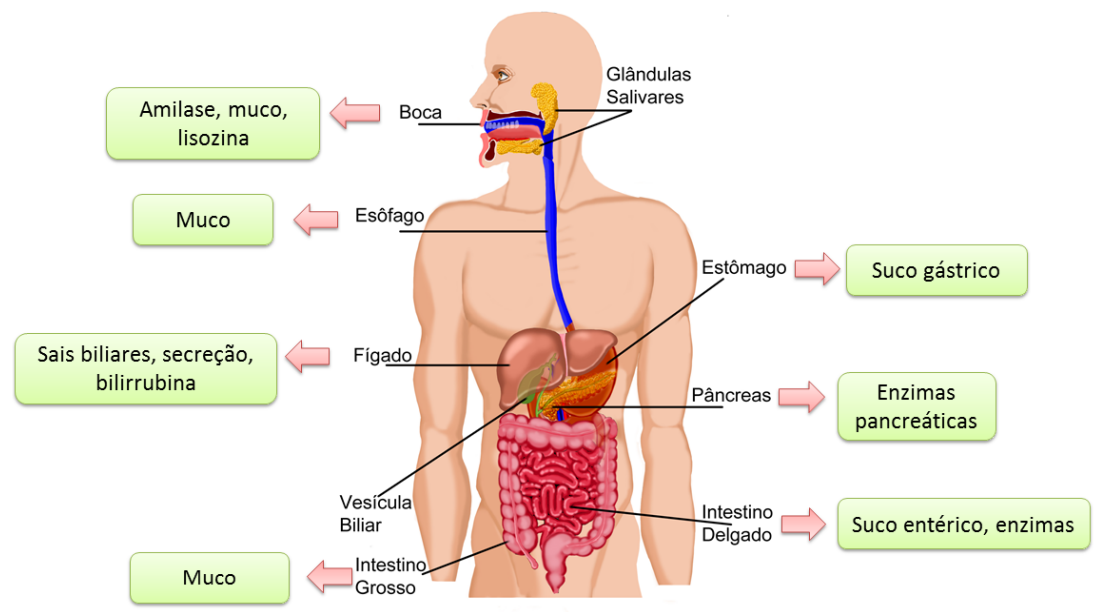

Figura 19.1 - A produção de secreções salivares e gastrintestinais no corpo humano.

\subsection{GLÂNDULAS SALIVARES E SALIVA}

As glândulas salivares consistem em uma série de ductos ramificados, acabando na porção secretora terminal, conhecida como ácino, de formato esférico ou tubular. O ducto excretor principal, que desemboca dentro da cavidade oral, divide-se progressivamente em ductos excretores menores interlobulares, que adentram nos lóbulos das glândulas. O componente predominante do ducto interlobular é o ducto estriado, que determina maior modificação da saliva primária (Nanci, 2008; Varga, 2012). Assim, os diversos ácinos são ligados por ductos intercalados, e a saliva secretada é drenada para a cavidade oral através de ductos estriados e excretores (Figura 19.2).

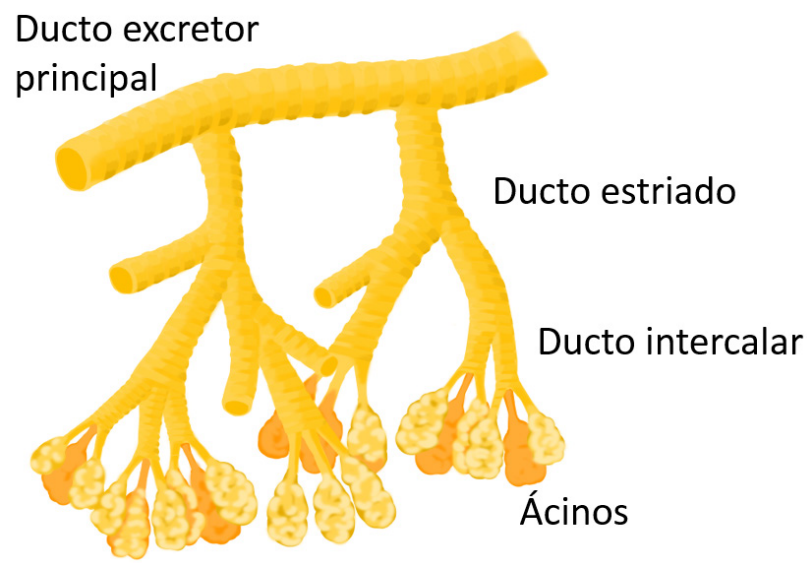

Figura 19.2 - llustração do sistema de ducto salivar maior. 
Os ácinos e as células dos ductos das glândulas salivares expressam vários receptores ionotrópicos e metabotrópicos $\mathrm{P} 2$, tanto no lúmen como nas membranas basais (Turner et al., 1999; Lee et al., 2012). Os receptores P2Y parecem ser mais importantes no desenvolvimento glandular e, talvez, também na sua reparação. Já os receptores P2X podem ter papel preponderante na secreção de fluidos e eletrólitos. Estudos têm mostrado que a estimulação dos receptores P2X7 expressos tanto nos ácinos como nas células dos ductos das glândulas salivares determina um aumento da concentração intracelular de $\mathrm{Ca}^{2+}$ (Li et al., 2003; Nakamoto et al., 2009; Novak; Jans; Wohlfahrt, 2010).

A saliva é um fluido aquoso encontrado na cavidade oral, composto por uma mistura complexa de produtos secretórios orgânicos e inorgânicos (Lima et al., 2010). Cerca de 90\% desse fluido oral originam-se de três pares de glândulas salivares maiores, as glândulas parótidas, as submandibulares e as sublinguais. Outras fontes responsáveis por sua composição final, aproximadamente $10 \%$, compreendem o sulco gengival, além de inúmeras glândulas salivares menores presentes na língua, mucosas labial, bucal e palatina, além de secreções da nasorofaringe (Aps; Martens, 2005), compostos derivados do sangue e de refluxo gastrointestinal (Dodds; Johnson; Yeh, 2005).

A saliva inicial é produzida nos ácinos das glândulas salivares, e estocada nos grânulos desses ácinos. Tais grânulos são preenchidos com água, nos quais eletrólitos e proteínas são dissolvidos (Aps; Martens, 2005). As células acinares são amplamente divididas em dois tipos: células serosas e mucosas. Assim, cada tipo de glândula produz uma secreção salivar típica. A glândula parótida produz um líquido seroso; a submandibular produz secreção mucoserosa, enquanto que as glândulas sublinguais secretam apenas saliva mucosa. As glândulas menores, situadas na mucosa bucal dos lábios e no palato, produzem secreções viscosas (Veerman et al., 1996).

Em condições basais, ocorre secreção de cerca de $0,5 \mathrm{ml}$ de saliva por minuto, variando de 0,5 a 1 litro de saliva por dia (Catalán; Nakamoto; Melvin, 2009), quase que totalmente do tipo mucoso, exceto durante o sono, quando a secreção é reduzida (Guyton; Hall, 2011). Nesse contexto, observa-se que a secreção salivar se torna extremamente importante para a manutenção da saúde dos tecidos orais, uma vez que o fluxo salivar contribui para a higiene desses tecidos, e também por que a saliva contém vários fatores capazes de destruir micro-organismos.

A saliva é um dos fluidos mais complexos, versáteis e importantes do corpo, compreendendo uma vasta extensão de necessidades fisiológicas (Lima et al., 2010). A saliva secretada possui papel multifuncional, pois na cavidade oral protege dentes e mucosa contra os efeitos prejudiciais de toxinas microbianas, de estímulos nocivos e de traumas menores decorrentes da presença alimentar, além de favorecer meio adequado para os receptores gustativos, e a capacidade 
de comunicação através da fala. Clinicamente, o papel mais relevante da saliva é a manutenção da saúde oral. Contudo, a saliva exerce ainda papel relevante na fisiologia esofágica, no processo digestivo e na proteção das células gástricas (Mese; Matsuo, 2007).

\subsection{FISIOLOGIA DA SALIVAC̣ÃO}

A presença de alimento na boca geralmente estimula as glândulas salivares à secreção. O sistema nervoso autônomo exerce um papel importante na salivação (Aps; Martens, 2005). Fisiologicamente, a secreção salivar é quase que totalmente controlada por esse sistema, onde nenhum hormônio usualmente inicia a salivação (Mese; Matsuo, 2007). Tanto um estímulo parassimpático como um simpático poderão produzir secreções a partir das glândulas parótidas e submandibulares. Raramente suas participações se farão na ausência de um estímulo autonômico, sendo a estimulação parassimpática a predominante (Som; Brandwein, 2003). A taxa de secreção salivar aumenta sinergicamente quando as glândulas são expostas simultaneamente a ambas estimulações autonômicas, ou seja, tanto estimulação colinérgica, como também alfa e beta-adrenérgicas das glândulas salivares são possíveis (Aps; Martens, 2005). A inervação parassimpática, via receptores colinérgicos acinares, é a responsável principal pela secreção de água e eletrólitos, enquanto a inervação simpática é responsável principalmente pela secreção de proteínas, acompanhadas por exocitose nas células acinares (Som; Brandwein, 2003).

A estimulação autonômica parassimpática, principalmente por ativação de receptores colinérgicos muscarínicos M3 e, em menor extensão, M1 (Proctor; Carpenter, 2007), envolve o sistema de transdução de sinais com liberação dos estoques intracelulares de $\mathrm{Ca}^{2+}$. $\mathrm{O}$ aumento dos níveis de $\mathrm{Ca}^{2+}$ intracelular conduz à abertura dos canais de $\mathrm{Cl}^{-}$na membrana apical e consequente secreção de $\mathrm{Cl}^{-}$no lúmen. A partir de então, por causa da eletronegatividade causada pela secreção de $\mathrm{Cl}^{-}$, ocorre a passagem de $\mathrm{Na}^{+}$através das zonas de oclusão (tight junctions) permeáveis a cátions nas células acinares, a fim de se preservar a eletroneutralidade (Mese; Matsuo, 2007). A secreção de $\mathrm{NaCl}$ cria, então, um gradiente osmótico através dos ácinos, o qual arrasta água a partir do suprimento sanguíneo. Desse modo, a saliva inicial secretada no lúmen (saliva primária) consiste em um fluido líquido com isotonicidade semelhante à do plasma. Conforme a hipótese de dois passos, a seguir, tal composição é modificada nos sistemas de ductos. Assim, durante a passagem da saliva por tais ductos, as concentrações de eletrólitos apresentam várias alterações devido ao transporte iônico (Aps; Martens, 2005; Guyton; Hall, 2011). Embora a secreção primária da saliva seja um ultrafiltrado plasmático, portanto, isotônico, a reabsorção dependente de energia de $\mathrm{Na}^{+}$e $\mathrm{Cl}^{-}$no sistema de ductos salivares e 
porque o epitélio do ducto é pobremente permeável a água, torna a secreção da saliva final marcantemente hipotônica (Dodds; Johnson; Yeh, 2005; Catalán; Nakamoto; Melvin, 2009). Tal hipotonicidade, no entanto, facilita a percepção dos sabores; o fluxo de bicarbonato permite o tamponamento, enquanto o fluxo de cálcio e fosfato permite a integridade mineral dos dentes (Varga, 2012). Quando ocorre refluxo a partir do estômago, ocasionalmente o ácido gástrico chega até a boca através do esôfago; o bicarbonato da saliva é o maior fator neutralizador contra os danos deletérios (Lee et al., 2012). Ainda, o pH salivar normal é, em média, 6,7, podendo variar de 5, 6 a 7, alterando-se diretamente com o $\mathrm{pH}$ do sangue (teor de $\mathrm{CO} 2$ ). A saliva final possui constituintes inorgânicos os quais incluem principalmente $\mathrm{Na}^{+}, \mathrm{Cl}^{-}, \mathrm{HCO}^{3-}, \mathrm{K}^{+}$e, em menor quantidade, $\mathrm{Ca}^{2+}, \mathrm{Mg}^{2+}$ e fosfato (Mese; Matsuo, 2007). Desse modo, a composição iônica e o pH podem influenciar a atividade dos constituintes orgânicos na saliva (Dodds; Johnson; Yeh, 2005).

A estimulação simpática, via receptores beta-adrenérgicos, causa exocitose, porém menos fluido é secretado. A ativação desses receptores aumenta os níveis intracelulares de adenosina 3', 5'-monofosfato cíclico (AMPc), o qual é primariamente um segundo mensageiro para a secreção de amilase. Tem sido descrito que o AMPc ativa proteínas quinases A (PKA), cujos alvos, embora não estejam completamente identificados, elas podem regular os processos pelos quais ocorrem liberação do conteúdo de seus grânulos secretórios. Sabe-se ainda que o conteúdo liberado compreende uma ampla variedade de proteínas, as quais são únicas para a saliva, com funções biológicas particularmente importantes para a homeostasia da cavidade oral (Mese; Matsuo, 2007). Não apenas o volume, mas também a composição da saliva final podem variar dependendo da contribuição das diferentes glândulas salivares durante uma estimulação reflexa. As glândulas parótidas contribuem com baixa taxa de salivação sob condições de repouso (de não estimulação), quando comparadas a situações de estimulação de tais glândulas. Em contraste, as glândulas submandibulares e sublinguais secretam relativamente mais saliva sob condições de repouso (Mese; Matsuo, 2007). Porém, mesmo quando não estimuladas, tais glândulas secretam um fluido, o qual é produzido por meio de vesículas (Aps; Martens, 2005).

A saliva humana é composta de $98 \%$ de água e os $2 \%$ restantes consistem de outros compostos, tais como os eletrólitos, lubrificantes (mucinas e proteínas ricas em prolina), compostos antimicrobianos (Imunoglobulina secretória A, aglutinina, lisozima, lactoferrina, lactoperoxidase salivar, cistatina, histatina, estaterina), várias enzimas (amilase, lipase, ribonuclease, protease) e fatores de crescimento [Fator de Crescimento Epidérmico (EGF), Fatores de Crescimento Transformador(TGF)- $\alpha$ e- $\beta$, Fator de Crescimento de Fibroblastos (FGF), Fatores 
de Crescimento insulina-like (IGF) I e II e Fator de Crescimento de Nervo (NGF)]. Estes componentes salivares facilitam a mastigação, a fala e a deglutição, e inicia o processo de digestão de certos tipos de alimentos por várias enzimas. Além disso, protege a mucosa oral e os dentes, e limpa as superfícies. Deste modo, qualquer condição que afete a composição e o volume de saliva secretada pode ter um impacto negativo sobre a região orofaríngea (Varga, 2012).

Dentre os constituintes orgânicos da saliva, destacam-se as mucinas, glicoproteínas que atuam como lubrificantes de alimentos, protegem a mucosa oral contra agentes bacterianos, virais ou fúngicos. Embora as glândulas salivares menores e sublingual, que secretam a maior parte do componente mucina da saliva, correspondam apenas a $10 \%$ do volume total de saliva, seu comprometimento funcional, por exemplo, devido a doenças autoimunes ou irradiação, resulta em xerostomia (Som; Brandwein, 2003).

As proteínas ricas em prolina são proteínas de massa molecular relativamente elevada, enquanto as estaterinas possuem tamanhos menores. Ambas as proteínas servem para prevenir a precipitação de fosfato de cálcio em cálculos salivares. Quando alcançam a cavidade oral, dada a sua propriedade de se ligar à superfície dentária, compõem o biofilme dental (Varga, 2012).

O componente adaptativo do sistema imune na saliva consiste de diferentes classes de imunoglobulinas (IgA, IgE, $\operatorname{IgG}, \operatorname{Ig} M)$. A atividade antibacteriana da saliva é realizada pela imunoglobulina secretória A (IgAs), além de enzimas como a lisozima, a peroxidase, a alfa-amilase e a lactoferrina, e de íons, tais como tiocianato e hidrogênio (Mese; Matsuo, 2007). A IgAs, em particular, é derivada das células plasmáticas diretamente no interstício das glândulas salivares e, continuamente, move-se para o lúmen. Estudos em animais têm demonstrado que a ativação reflexa simpática pouco ou nenhum efeito causa nas concentrações secretadas dessa imunoglobulina (Matsuo et al., 2000). Somando-se à IgAs nas defesas inatas contra micro-organismos, encontram-se as lisozima, lactoperoxidase e lactoferrina. A lisozima rompe a parede de bactérias gram-positivo (Varga, 2012). Esta enzima, descoberta casualmente por Alexander Fleming, foi a primeira a ter sua estrutura revelada (Figura 19.3A). A capacidade desta enzima em combater bactérias deve-se ao fato de que a estrutura da parede bacteriana contém segmentos para os quais existe afinidade no sítio ativo da lisozima. Ao serem expostos um ao outro, as interações moleculares favorecem a quebra da estrutura da parede bacteriana. Para compreender como isso acontece, pode-se expor a estrutura atômica dessa enzima com mais detalhe (Figura 19.3B). Neste caso, uma mutação em um dos aminoácidos da estrutura original permitiu registrar cristalograficamente um passo intermediário no qual um dos anéis presentes na estrutura da parede bacteriana apresenta-se distorcido (Figura 19.3B, circulado em vermelho). Sugere-se que esta é uma etapa essencial do processo catalítico (Kuroki et al., 1993). 

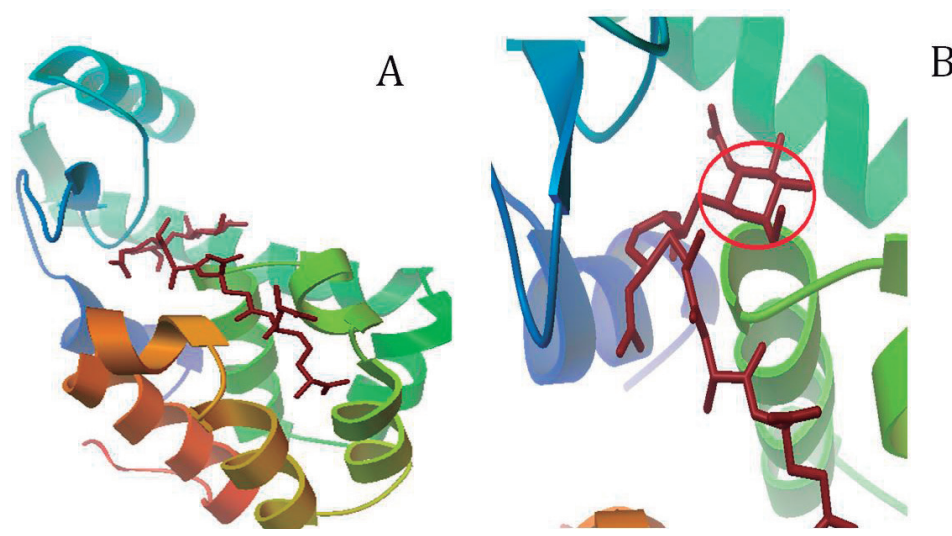

Figura 19.3 - Modelo estrutural da lisozima. (A) Na cor vinho, um fragmento de parede bacteriana; (B) detalhe da modificacãao proposta para a estrutura da parede bacteriana sob atuaç̃ão da lisozima. Nesta situacçoo, 0 anel circulado em vermelho encontra-se mais aplanado (Baseado em Sanner, 1999; PMV-MGLTools, v. 1.5.6, para Windows).

A lactoperoxidase oxida o tiocinato, da saliva, em hipotiocinato, um poderoso agente antibacteriano. A lactoferrina é uma glicoproteína ligadora de metais na saliva, no leite e em outras secreções exócrinas, assim como em grânulos neutrofílicos. A lactoferrina possui um número considerável de funções biológicas, incluindo, além de efeito antimicrobiano, atividade imunomodulatória. De fato, a inibição do crescimento da C. albicans decorre do aumento do número de leucócitos e da resposta de citocinas nos linfonodos regionais contra infecção fúngica (VARGA, 2012). Somando-se a esse efeito, as histatinas exibem atividade citotóxica contra C. albicans por causar mudanças estruturais na parede da membrana celular, induzindo sua desintegração (VARGA, 2012). Ainda, a saliva é conhecida como "fonte da vida" devido ao seu bem conhecido efeito cicatrizante de feridas. Esta atividade decorre principalmente ao fato de que as glândulas salivares produzem e secretam uma quantidade extremamente elevada de EGF na cavidade oral, exibindo efeitos citoprotetores e proliferativos, não apenas para a mucosa oral, como também para o esôfago e parte baixa do trato gastrointestinal. Em pequenas quantidades, outros fatores de crescimento, tais como TGF- $\alpha$, TGF- $\beta$, FGF, IGF-I, IGF-II e NGF, também são relatados em várias concentrações na saliva (VARGA, 2012).

A saliva é também importante para o processo digestivo. A mastigação de alimentos estimula a secreção de saliva pelas glândulas principais, provocando um aumento do fluxo salivar e da concentração de amilase. O fluxo de água aumenta e a concentração de amilase elevada facilitam o clearence de restos alimentares e a digestão, respectivamente. A amilase salivar hidrolisa ligações $O$-glicosídicas de amido e o divide em fragmentos menores e hexoses simples (VARGA, 2012). A 
simplificação do amido produzida pela atividade da alfa-amilase favorece a atividade metabólica das bactérias, que produzem ácidos a partir da maltose. Estes ácidos estão implicados no ataque ao esmalte dentário, no processo que culmina em cáries. Ainda, a alfa-amilase também exibe capacidade de ligação à hidroxiapatita e ligação a bactérias. Tem-se demonstrado que esta enzima é também um fator importante para a colonização bacteriana, como no caso do Streptococcus gordonii. Embora o sítio ativo para hidrólise do amido esteja bem caracterizado, há ainda um esforço da pesquisa para definir melhor o segmento molecular implicado na ligação às bactérias (RAGUNATH et al., 2008). Uma representação da estrutura da alfa-amilase salivar produzida a partir dos dados publicados por estes autores aparece na Figura 19.4. Sua ação, porém, é limitada, uma vez que é apenas ativa acima de $\mathrm{pH}$ 6,0. Portanto, a amilase salivar é inativada quando se atinge o ambiente ácido do estômago. A digestão do amido, então, é completada pela amilase pancreática no intestino delgado. A lipase também é secretada pela glândula parótida e pelas glândulas linguais de von Ebner, mas apenas em uma quantidade bastante limitada. Por isso, o seu real papel fisiológico ocorre durante os primeiros meses após o nascimento, quando o pâncreas imaturo é incapaz de produzir atividade lipolítica necessária para digerir a pequena quantidade de gordura no leite (VARGA, 2012).

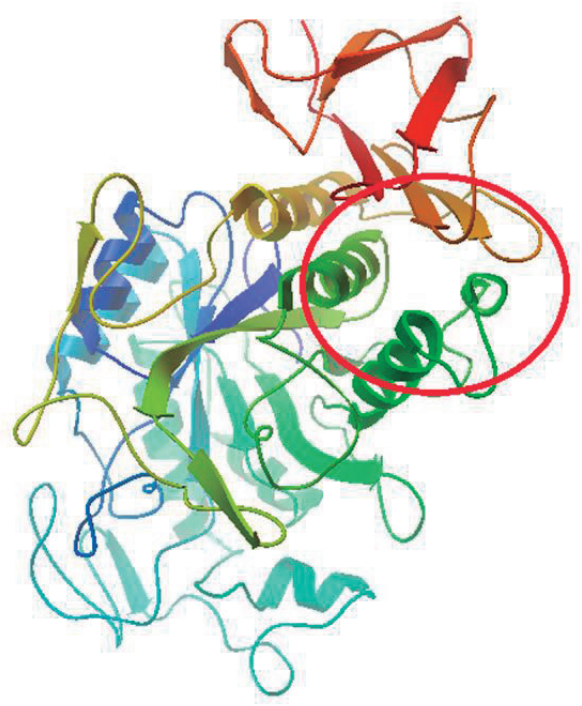

Figura 19.4 - Modelo estrutural da amilase salivar. Em vermelho vivo, o local aproximado do sítio ativo (Baseado em Sanner, 1999; PMV-MGLTools, v. 1.5.6, para Windows).

A análise salivar tornou-se um importante recurso para a avaliação das condições salivares com implicações fisiológicas e patológicas e tem sido um meio 
útil para o diagnóstico de doenças, principalmente devido a sua origem, composição, funções e interações com outros sistemas orgânicos. Além disso, tal análise envolve um método de coleta simples, não invasivo, de fácil armazenagem e de baixo custo, quando comparado às coletas sanguíneas ou outros fluidos biológicos (MALATHI et al, 2014). Com o advento recente de técnicas e equipamentos de instrumentação química modernos houve um aumento observável no seu uso para investigações laboratoriais, aplicáveis para fins básicos e clínicos na odontologia e em outras áreas médicas. O valor da saliva como uma ferramenta de diagnóstico para doenças orais e sistêmicas tem sido uma área de estudo para muitos pesquisadores, com o objetivo de aumentar a sua utilização como um possível exame complementar de rotina (Lima et al., 2010). Dentre as diversas possibilidades de uso de saliva como meio de diagnóstico de doenças, têm-se as medidas de funções digestivas, tamponamento, remineralização e prevenção de desmineralização dentária, lubrificação e proteção contra micro-organismos. Clinicamente, ainda, a saliva pode contribuir para análises proteômica, genômica, transcriptômica, dentre outras. Em suma, o diagnóstico por meio salivar pode contribuir para a detecção de desordens genéticas, infecções, neoplasias malignas, doenças renais e autoimunes, como marcadores de turnover ósseo e cardiovascular, doenças periodontais e cáries, doenças do córtex adrenal, útil ainda para monitoramento de fármacos e como evidências forenses (MALATHI et al, 2014).

\subsection{ESÔFAGO E SECREÇÃO ESOFÁGICA}

O esôfago é um tubo muscular de cerca de $25 \mathrm{~cm}$ de comprimento, que se estende desde a $6^{\text {a }}$ vértebra cervical até a $11^{\text {a }}$ vértebra torácica, abrangendo três regiões anatômicas (PATTI; GANTERT; WAY, 1997; GAVAGHAN, 1999). O esôfago cervical parte da linha média, posterior à laringe e à traqueia, e anterior à camada pré-vertebral da fáscia cervical. A porção superior do esôfago torácico curva ligeiramente para a direita e passa por trás da bifurcação traqueal e à esquerda do brônquio. A porção inferior do esôfago torácico segue por atrás do pericárdio e do átrio esquerdo, onde ele se curva para a esquerda e entra no abdômen através do hiato esofágico. Nesse caso, esôfago abdominal, medindo 2 a 4 $\mathrm{cm}$ de comprimento, termina na sua junção com o estômago. Existem ainda três áreas de estreitamento normal do lúmen esofágico: a cartilagem cricoide; brônquio principal esquerdo e arco aórtico, onde o esôfago é comprimido por essas estruturas, e o hiato diafragmático (PATTI; GANTERT; WAY, 1997). As funções motoras do esôfago resultam de interações de uma variedade de mecanismos de controle. Tais mecanismos ligam a função do esôfago a aspectos de deglutição, a funções motoras gástricas, a outros órgãos torácicos e ao sistema nervoso central, isto é, as funções esofágicas incluem a facilitação do transporte de alimentos 
para o estômago e a prevenção de refluxo do conteúdo gástrico para o esôfago e à faringe (CLOUSE; DIAMANT, 2006). Baseado em sua função, o esôfago pode ser pensado como três estruturas: o esfíncter esofágico superior (EES), o corpo do esôfago propriamente dito e o esfíncter esofágico inferior (EEI). Suas atividades coordenadas são responsáveis pela performance motora do esôfago (PATTI; GANTERT; WAY, 1997).

As glândulas submucosas esofágicas são estruturas importantes dentro da parede do esôfago humano e de muitas outras espécies. O corpo principal do esôfago é revestido com muitas glândulas mucosas simples. No terminal gástrico e em uma pequena extensão na porção inicial do esôfago, há, contudo, muitas glândulas mucosas compostas (GUYTON; HALL, 2011). Elas parecem funcionar em alguma extensão tais como as glândulas salivares, visto que secretam seus produtos para o lúmen do trato digestivo, sendo úteis para uma variedade de funções de proteção. A regulação das glândulas submucosas esofágicas parecem estar sob o controle do nervo vago, mas, ao contrário das glândulas salivares, praticamente apenas as terminações colinérgicas parassimpáticas parecem exercer um efeito estimulador (LONG; ORLANDO, 1999). A deglutição também combina processos voluntários e involuntários atuando em conjunto: a fase orofaríngea inicialmente é voluntária, mas se torna involuntário o seguimento da atividade motora do esôfago (CLOUSE; DIAMANT, 2006).

As secreções esofágicas são inteiramente mucosas e fornecem principalmente a lubrificação para a deglutição. O muco produzido pelas glândulas compostas no esôfago superior evita a escoriação da mucosa causada pela passagem de alimento, enquanto que as glândulas compostas localizadas próximas à junção esofagogástrica protegem a parede esofágica da digestão por sucos gástricos ácidos que geralmente refluem do estômago para o esôfago inferior (GUYTON; HALL, 2011). De fato, a função clinicamente mais relevante das glândulas submucosas esofágicas é a sua capacidade de aumentar a secreção de bicarbonato em resposta ao ácido no seu lúmen, embora careça ser esclarecido se tal resposta à acidificação esofágica é unicamente decorre da secreção das glândulas submucosas esofágicas ou se é também um subproduto da lesão tecidual induzida por ácidos (LONG; ORLANDO, 1999). A despeito dessa proteção, eventualmente pode se desenvolver uma úlcera péptica na terminação gástrica do esôfago (GUYTON; HALL, 2011).

\subsection{ESTÔMAGO E SECREC̣ÃO GÁSTRICA}

O estômago é constituído por três regiões anatômicas (fundo, corpo e antro) e duas regiões funcionais (mucosas glandulares oxíntica e pilórica) (CHU; SCHUBERT, 2012), além de células secretoras de muco que revestem toda a sua 
superfície (GUYTON; HALL, 2011). Essa região funcional é formada por glândulas tubulares oxínticas ou gástricas, localizadas nas superfícies internas do corpo e do fundo do estômago, constituindo $80 \%$ do estômago proximal, bem como por glândulas tubulares pilóricas, localizadas na porção antral do estômago, correspondente aos 20\% distais deste órgão (GUYTON; HALL, 2011). Tais unidades funcionais são divididas em fenda (pit), istmo, pescoço e base, sendo as células-tronco e as células progenitoras localizadas no istmo das glândulas (CHU; SCHUBERT, 2012).

Basicamente, as glândulas oxínticas, do grego oxys que significa ácido, secretam ácido clorídrico, pepsinogênio, fator intrínseco e muco (GUYTON; HALL, 2011; SCHUBERT, 2001). As glândulas pilóricas secretam principalmente muco, assim como o hormônio gastrina (GUYTON; HALL, 2011). Entre essas glândulas, a superfície da mucosa estomacal possui ainda uma camada contínua de um tipo especial de células denominadas de células mucosas superficiais, que secretam grandes quantidades de um muco muito viscoso e alcalino, constituído por mucoproteínas e mucopolissacarídeos, de forma que uma camada gelatinosa de muco adere à mucosa do estômago. Tal camada proporciona uma barreira de proteção, muitas vezes com mais de um milímetro de espessura, para a parede estomacal, protegendo-a contra a abrasão promovida pelos alimentos sólidos e contra o ácido do lúmen do estômago, bem como contribuindo para a lubrificação do transporte de alimento. A proteção ácida é também conferida pelos íons bicarbonato $\left(\mathrm{HCO}^{-}\right)$secretados nessa camada mucosa e conferem a esta um $\mathrm{pH}$ ligeiramente alcalino. A alcalinidade desse muco impede, ainda, que a parede do estômago seja exposta à secreção proteolítica altamente ácida desse órgão, uma vez que a pepsina requer um $\mathrm{pH}$ inferior a cinco para permanecer ativa. Assim, é importante que essa camada de muco esteja em contínua renovação, pois, de outra forma, o ácido pode promover eventuais ulcerações. Irritações locais da mucosa aumentam a secreção de muco e de $\mathrm{HCO} 3$, mediante a produção de prostaglandinas no local, de modo que fármacos anti-inflamatórios que inibem a produção de prostaglandinas limitam a renovação dessa barreira mucosa. As catecolaminas também podem contribuir para a formação de úlceras, uma vez que inibem a secreção de HCO3. Por fim, o álcool aumenta a produção de ácido e, se suficiente, pode superar essa barreira mucosa (GUYTON; HALL, 2011; FRY, 2009).

\subsubsection{SECREÇÃO DAS GLÂNDULAS OXÍNTICAS}

As glândulas oxínticas são formadas por diversos tipos de células que diferem em suas localidades e secreções: as células mucosas localizadas no pescoço das glândulas, que secretam basicamente muco; as células pépticas ou principais, localizadas predominantemente na base das glândulas, que secretam grandes quantidades de pepsinogênio; e células parietais ou oxínticas, localizadas em 
todas as regiões das glândulas, que secretam ácido clorídrico e fator intrínseco (GUYTON; HALL, 2011; SCHUBERT, 2001; 2002). Essas células parietais, embora estejam predominantemente presentes na mucosa oxíntica (fundo e corpo do estômago), também são encontradas no antro, em até $50 \%$ das glândulas antrais, correspondendo a 5\% do total dessas células (CHOI et al, 2014; SCHUBERT, 2015). Células neuroendócrinas também são encontradas na base das glândulas oxínticas, como as células enterocromafins, responsáveis pela síntese de serotonina, peptídeo natriurético atrial e adrenomedulina; as células semelhantes às enterocromafins, produtoras de histamina; as células $\mathrm{D}$, produtoras de somatostatina; e células tipo A ou Gr, produtoras de grelina (SCHUBERT, 2001; CHU; SCHUBERT, 2012). Dentre todas essas células da mucosa oxíntica, as predominantes são as parietais e as semelhantes às enterocromafins (CHU; SCHUBERT, 2012).

O ácido clorídrico facilita a digestão de proteínas pela conversão do pepsinogênio à enzima proteolítica ativa, pepsina. Além disso, o ácido clorídrico facilita a absorção de ferro, cálcio, vitamina B12, certas medicações, bem como previne o crescimento bacteriano excessivo, infecções entéricas e, possivelmente, pneumonia adquirida na comunidade, peritonite bacteriana espontânea e alergia alimentar mediada por IgE (CHU; SCHUBERT, 2012; Schubert, 2015). Juntamente com o ácido clorídrico, é secretada pelas células parietais a substância fator intrínseco, essencial para absorção de vitamina B12 no íleo (GUYTON; HALL, 2011).

Existem vários tipos de pepsinogênio, que, apesar de ligeiramente diferentes, realizam as mesmas funções. São secretados não somente pelas células pépticas das glândulas gástricas, mas também pelas células mucosas. O pepsinogênio não possui atividade digestiva, entretanto, assim que entra em contato com ácido clorídrico é clivado para formar pepsina ativa. Assim, a pepsina atua como uma enzima proteolítica ativa em meio muito ácido ( $\mathrm{pH}$ ideal entre 1,8 e 3,5), tornando-se completamente inativada em pouco tempo em um pH acima de 5 (GUYTON; HALL, 2011).

\subsubsection{SECREÇÃO DAS GLÂNDULAS PILÓRICAS}

As glândulas pilóricas são tubulares com estrutura semelhante às oxínticas, no entanto, apesar de possuírem células D, enterocromafins, células tipo A ou Gr, poucas células pépticas e quase nenhuma célula parietal, são essencialmente formadas por células mucosas, que secretam grande quantidade de muco e uma pequena quantidade de pepsinogênio (GUYTON; HALL, 2011; CHU; SCHUBERT, 2012). O pepsinogênio é produzido, portanto, pela mucosa oxíntica (pepsinogênio I e II) e, adicionalmente, pela mucosa pilórica, assim como pelo duodeno (pepsinogênio II) (HOU; SCHUBERT, 2006; SCHUBERT 2011). Além disso, a marca da mucosa pilórica são as células da gastrina, também chamadas de células G, responsáveis por secretarem o hormônio gastrina e encontradas tanto na base das glândulas pilóricas como no duodeno. Basicamente, a gastrina tem um papel 
crucial no controle da secreção gástrica, sendo liberada em resposta aos alimentos proteicos, bem como denota propriedade trófica para as células da mucosa (GUYTON; HALL, 2011; CHU; SCHUBERT, 2012). Uma quantidade maior do que $95 \%$ da gastrina secretada é aminada, com $85 \%$ desta sendo um peptídeo com 17 aminoácidos (G-17), 5-10\% um peptídeo com 34 aminoácidos (G-34) e o restante uma mistura com peptídeos tanto maiores como menores que estes (CHU; SCHUBERT, 2012).

\subsubsection{FISIOLOGIA DA SECREÇÃO GÁSTRICA}

\subsubsection{FORMAÇÃO E SECREÇÃO DE ÁCIDO CLORÍDRICO}

A taxa de secreção de ácido gástrico varia entre jejum e alimentação, mas, quando estimuladas, as células parietais secretam uma solução ácida com cerca de 160 milimoles de ácido clorídrico por litro $(\mathrm{pH}=0,8)$, que é quase exatamente isotônica aos líquidos corporais. Neste $\mathrm{pH}$, a concentração de íons hidrogênio é aproximadamente três milhões de vezes maior do que a do sangue arterial. $\mathrm{O}$ principal ânion dessa secreção é o $\mathrm{Cl}^{-}$. A célula parietal é altamente especializada com um sistema de canalículos intracelulares ramificados que formam projeções em vilos, nas quais o ácido clorídrico é formado, e que aumentam muito a área de superfície apical dessa célula. Essa área de superfície aumenta ainda mais quando a produção de ácido é estimulada. O ácido formado e armazenado nessa área segue através dos canalículos até a abertura secretora da célula (GUYTON; HALL, 2011; FRY, 2009).

O mecanismo básico para a formação do ácido clorídrico envolve várias etapas. O íon cloreto é transportado do citoplasma da célula parietal para o lúmen do canalículo e os íons sódio são transportados do canalículo para o citoplasma da célula parietal. Ambos os transportes são ativos e em conjunto criam um potencial negativo de -40 a -70 milivolts no canalículo, o que promove a difusão de íons carregados positivamente do citoplasma para o interior do canalículo, mais especificamente $\mathrm{K}^{+}$e um pequeno número de $\mathrm{Na}^{+}$, formando cloreto de potássio e quantidades menores de cloreto de sódio no interior do canalículo. Íons hidrogênio, decorrentes da dissociação da molécula de água em $\mathrm{H}^{+}$e $\mathrm{OH}^{-}$(hidroxila) no citoplasma celular, são ativamente secretados no canalículo em troca de $\mathrm{K}^{+}$(GUYTON; HALL, 2011). Este processo de troca ativa é catalisado pela bomba de prótons $\mathrm{H}^{+} \mathrm{K}^{+}$-ATPase, que, no estado de repouso está sequestrada na sua forma inativa dentro de túbulo-vesículas citoplasmáticas. A estimulação da secreção gástrica, no entanto, resulta no aumento intracelular de AMPc e na sinalização dependente de cálcio que promovem o recrutamento e fusão dessas vesículas com a membrana apical da célula e o início da troca 
de íons (SCHUBERT, 2010; CHU; SCHUBERT, 2012; SCHUBERT, 2015). As proteínas envolvidas na translocação e fusão da bomba de prótons $\mathrm{H}^{+} \mathrm{K}^{+}$-ATPase incluem a miosina, actina, Rab GTPases e ezrina. Por outro lado, a cessação do estímulo secretório promove a recuperação e internalização das vesículas (SCHUBERT, 2010, 2014, 2015; CHU; SCHUBERT, 2012). Assim, em decorrência dessa troca iônica, grande parte dos íons $\mathrm{K}^{+}$e $\mathrm{Na}^{+}$que foi difundido no canalículo é reabsorvida para o citoplasma, e os íons $\mathrm{H}^{+}$tomam seu lugar no canalículo. Esse íon $\mathrm{H}^{+}$associa-se com os íons $\mathrm{Cl}^{-}$presentes no canalículo, gerando uma solução forte de ácido clorídrico, que é, então, secretado para o exterior através da abertura do canalículo no lúmen da glândula (GUYTON; HALL, 2011).

Devido aos íons extras secretados no canalículo, a água também passa por osmose para o interior deste. Assim, além do ácido clorídrico, em uma concentração aproximada de 150 a $160 \mathrm{mEq} / \mathrm{l}$, a secreção final do canalículo contém água, cloreto de potássio a uma concentração de $15 \mathrm{mEq} / \mathrm{l}$ e uma pequena quantidade de cloreto de sódio. Por fim, ocorre a formação de íons bicarbonato, em decorrência da interação do dióxido de carbono, formado durante o metabolismo celular ou proveniente da entrada na célula pelo sangue, com íons hidroxila sob a influência da anidrase carbônica. Os íons bicarbonato difundem-se para fora do citoplasma para o líquido extracelular em troca de íons cloreto, que são secretados para o canalículo (GUYTON; HALL, 2011).

\subsubsection{REGULAÇÃO DA SECREÇÃO DE ÁCIDO PELO ESTÔMAGO}

A secreção gástrica de ácido é regulada por vias aferentes e eferentes dos sistemas nervosos central e entérico, assim como por mecanismos neuroendócrinos e células do sistema imune que atuam por vias autócrinas, parácrinas e hormonais. Essas vias convergem para quatro células essenciais para a secreção ácida: células parietais da mucosa oxíntica, que são as responsáveis pela produção de ácido clorídrico; células semelhantes às enterocromafins, também ocorrentes na mucosa oxíntica, e responsáveis pela síntese de histamina, substância principal para estimulação parácrina da secreção de ácido; células $\mathrm{G}$ das glândulas pilóricas, produtoras de gastrina, principal estimulante hormonal da secreção ácida; e células $\mathrm{D}$, nas mucosas oxíntica e pilórica, e responsáveis pela síntese de somatostatina, o principal inibidor parácrino da secreção de ácido clorídrico (SCHUBERT, 2004).

Resumidamente, os maiores responsáveis pela secreção ácida gástrica são a histamina, a gastrina e acetilcolina, sejam agindo de forma direta nas células parietais ou estimulando-as indiretamente. No entanto, outras substâncias podem estimular a liberação de ácido, como a grelina, o glutamato e o peptídeo ativador da adenilato ciclase pituitária (SCHUBERT, 2011; 2015). A acetilcolina, liberada 
por neurônios pós-ganglionares do sistema nervoso entérico, estimula as células parietais diretamente via receptores muscarínicos 3 (M3) e indiretamente via receptores muscarínicos 2 e 4 (M2 e M4), estes últimos relacionados a inibição da secreção de somatostatina e, consequente aumento da secreção de histamina e gastrina (SCHUBERT, 2007; 2011; 2015).

A histamina produzida pelas células semelhantes às enterocromafins estimula a secreção ácida de forma parácrina, uma vez que é liberada por tais células no espaço adjacente às células parietais das glândulas, alcançando-as por difusão e estimulando-as diretamente via receptores $\mathrm{H} 2$ e indiretamente pela ativação dos receptores $\mathrm{H} 3$, relacionados à inibição da secreção de somatostatina e, assim, ao aumento da secreção de histamina e gastrina (GUYTON; HALL, 2011; SCHUBERT, 2005; CHU; SCHUBERT, 2012). Provavelmente, o mecanismo mais potente de estimulação da secreção de histamina seja o hormônio gastrina, produzido em decorrência da proteína nos alimentos em digestão; no entanto, as células semelhantes às enterocromafins podem ser estimuladas também pela acetilcolina liberada pelas terminações nervosas vagais do plexo entérico do estômago e, provavelmente, por outras substâncias hormonais secretadas pelo sistema nervoso entérico da parede estomacal (GUYTON; HALL, 2011).

A gastrina é secretada não somente pelas proteínas, mas também devido a outros estímulos químicos, como pH elevado, e a estímulos mecânicos, como a distensão gástrica, que agem diretamente nas células $\mathrm{G}$ ou indiretamente via células neuroendócrinas e neurônios adjacentes (SCHUBERT, 2010). A gastrina liberada nos sucos digestivos do estômago é rapidamente transportada para as células semelhantes às enterocromafins, estimulando assim a liberação de histamina e, consequente liberação de ácido clorídrico (GUYTON; HALL, 2011). Em nível molecular, tal efeito é mediado pela ligação da gastrina ao receptor CCK-2 encontrado tanto nas células semelhantes às enterocromafins, como nas células parietais e nas células D (SCHUBERT, 2007).

O principal inibidor da secreção ácida gástrica é a somatostatina, produzida pelas células D nas glândulas oxínticas e pilóricas. Atua de forma parácrina e inibe as células parietais direta e indiretamente, ao inibir a secreção de histamina pelas células semelhantes às enterocromafins e de gastrina pelas células $G$, exercendo, portanto, uma ação tônica nessas células durante o período interdigestivo, de modo a manter a secreção ácida gástrica a um nível economicamente baixo. As ações biológicas da somatostatina são mediadas por seis receptores acoplados à proteína $G$, que são codificados por cinco genes denominados sst1-sst5. O subtipo 2 do receptor de somatostatina (SSTR2) é o mais amplamente distribuído e está envolvido nessa regulação da secreção ácida gástrica (SCHUBERT, 2004; 2010; 2011; 2015). Outros inibidores da secreção ácida incluem a colecistocinina (CCK, do inglês cholecystokinin) e o peptídeo semelhante ao glucagon 1 (GLP-1, do inglês glucagon-like peptide-1). A CCK atua estimulando, via ligação ao seu receptor (CCK-1R), a liberação de somatostati- 
na. O GLP-1 também inibe a liberação de ácido ao atuar em seu receptor (GLP-1R), encontrado tanto nas células parietais da mucosa oxíntica, como nas célula neuroendócrinas da mucosa pilórica (SCHUBERT, 2015).

\subsubsection{REGULAÇÃO DA SECREÇÃO DE PEPSINOGÊNIO}

Durante o processo digestivo, a liberação da acetilcolina pelos neurônios colinérgicos intramurais provavelmente seja o estimulante fisiológico mais importante para a secreção de pepsinogênio. Essa estimulação colinérgica é mediada por receptores muscarínicos 1 e 3 (M1 e M3) (HOU; SCHUBERT, 2006). Além disso, as células pépticas também podem ser estimuladas a secretarem pepsinogênio pelo ácido no estômago, embora, o ácido provavelmente não as estimule diretamente, mas sim provoque outros reflexos entéricos que amplifiquem os sinais nervosos para essas células (GUYTON; HALL, 2011).

Em termos moleculares, a secreção de pepsinogênio pelas células pépticas é mediada por pelo menos duas vias principais de transdução de sinais: 1) AMPc, com consequente ativação de proteína quinase; 2) aumento dos níveis intracelulares de cálcio, derivado tanto de reservas intracelulares quanto do meio extracelular (SCHUBERT, 2000).

\subsubsection{INTEGRAÇÃO DA PRODUÇÃO DA SECREÇÃO GÁSTRICA}

Quando o estômago está vazio, ocorre uma secreção gástrica basal, que corresponde a aproximadamente $10 \%$ da taxa máxima, sendo maior durante a noite. Essa secreção é em geral quase que inteiramente do tipo não-oxíntico, composta basicamente de muco, pouca pepsina e quase nenhum ácido. Estímulos emocionais, no entanto, aumentam a secreção gástrica nesse período interdigestivo e acredita-se que seja um dos fatores responsáveis pelo desenvolvimento de úlceras pépticas. Após uma refeição, a secreção aumenta rapidamente e ocorre em três fases: cefálica, gástrica e intestinal (GUYTON; HALL, 2011; FRY, 2009).

A fase cefálica da secreção gástrica inicia-se mesmo antes do alimento alcançar o estômago, enquanto está sendo digerido e é resultante da visão, do odor, da lembrança ou do sabor do alimento. Outros fatores como a hipoglicemia no sangue arterial cerebral também evocam secreção gástrica. Essa fase é mediada pelo nervo vago, e quanto maior o apetite, mais intensa é a estimulação. O controle central da secreção gástrica é complexo, no entanto, os sinais neurogênicos que causam a fase cefálica são originados no córtex cerebral e nos centros do apetite da amígdala e do hipotálamo, sendo transmitidos até o estômago pelos núcleos motores dorsais do nervo vago. Fibras e neurônios co- 
linérgicos do plexo intramural liberam acetilcolina que ativa as células parietais, bem como estimula a liberação de histamina e gastrina. Essa fase da secreção normalmente contribui com cerca de $20 \%$ da secreção gástrica associada à ingestão de uma refeição (GUYTON; HALL, 2011; FRY, 2009).

A maior parte da secreção ocorre na fase gástrica, correspondendo a aproximadamente $70 \%$ da secreção gástrica total associada à ingestão de uma refeição. Os principais fatores estimuladores são a distensão do estômago pela presença do alimento e a de produtos proteicos da digestão. Assim, receptores de estiramento na parede do estômago iniciam uma resposta local, entérica e central, com reflexos vasovagais longos do estômago para o cérebro e de volta para o estômago. Em relação aos produtos da digestão de proteínas, tem-se que aminoácidos e pequenos peptídeos estimulam a secreção de ácido por estimularem a secreção de gastrina. Outros compostos da comida, como cafeína e álcool também estimulam a secreção ácida (GUYTON; HALL, 2011; FRY, 2009).

Mesmo após o alimento sair do estômago, a secreção gástrica continua, em sua fase intestinal. O quimo no duodeno estimula a secreção de pequenas quantidades de suco gástrico, devido ao mecanismo de distensão do intestino e em razão de aminoácidos e peptídeos, que estimulam as células $G$ intestinais a secretarem gastrina. Essa gastrina, portanto, promove a liberação de ácido pelas células parietais estomacais. Após algum tempo, no entanto, o alimento no intestino delgado inibe a secreção gástrica, pois se inicia um reflexo enterogástrico reverso, transmitido através do sistema nervoso mioentérico, dos nervos vagos e simpáticos extrínsecos. Tal reflexo pode ser iniciado por distintos estímulos, como a distensão da parede do intestino, por ácido no intestino superior, pelos produtos da hidrólise de proteínas e pela irritação da mucosa (GUYTON; HALL, 2011; FRY, 2009).

A liberação de hormônios intestinais também está relacionada com essa inibição da secreção gástrica. O aumento da acidez do quimo, pelo próprio esvaziamento estomacal, as gorduras, produtos da digestão de proteínas, líquidos hiperosmóticos ou hiposmóticos ou qualquer fator irritante no intestino delgado superior são fatores que promovem a liberação desses hormônios intestinais e que, portanto, inibem a secreção gástrica. A secretina é um desses hormônios liberados no duodeno que exerce efeitos inibitórios sobre as células $\mathrm{G}$ e as células parietais, ativando um reflexo inibitório local. Alguns outros hormônios também denotam efeitos leves a moderados sobre a inibição da secreção gástrica, como o peptídeo inibidor gástrico, o polipeptídeo intestinal vasoativo, a somatostatina e a colecistocinina (Guyton; Hall, 2011; Fry, 2009).

\subsection{PÂNCREAS E SECREC̣ÃO PANCREÁTICA}


O pâncreas é uma grande glândula composta, localizada sob o estômago, com uma parte endócrina e outra exócrina, desenvolvidas a partir das superfícies ventral e dorsal do intestino anterior primitivo, respectivamente (LEE et al, 2012). A porção endócrina é composta por células organizadas em ilhotas que estão espalhadas por toda a glândula. Tais ilhotas possuem células alfa produtoras de glucagon; células beta, responsáveis pela secreção de insulina; células delta que liberam somatostatina; e células $\mathrm{PP}$, que produzem o polipeptídeo pancreático (CHANDRA; LIDDLE, 2009, 2014). A porção exócrina, em contrapartida, secreta principalmente enzimas digestivas e grandes volumes de solução de bicarbonato de sódio, no intestino delgado (GUYTON; HALL, 2011; CHANDRA; LIDDLE, 2014). Essa porção é composta por dois tipos principais de células, as acinares, que compreendem $90 \%$ do pâncreas exócrino; e as ductais, que compreendem apenas $10 \%$ das células pancreáticas em número e $5 \%$ do peso total do pâncreas (LEE et al., 2012; ISHIGURO et al, 2012).

A produção diária de suco pancreático é em torno de dois a três litros e consiste em um fluido isotônico alcalino, que contém uma variedade de enzimas digestivas e outras proteínas, como a lactoferrina (ISHIGURO et al, 2012). Essas enzimas são secretadas pelos ácinos pancreáticos com uma pequena quantidade de fluido rico em $\mathrm{Cl}^{\text {}}$, enquanto os ductos secretam bicarnonato de sódio (GUYTON; HALL, 2011; ISHIGURO et al, 2012). Assim, a secreção pancreática contém enzimas capazes de digerir proteínas, carboidratos e lipídeos, bem como grandes quantidades de íons bicarbonato, que neutralizam a acidez do quimo transportado do estômago para o intestino. Esse produto combinado de enzimas e bicarbonato de sódio flui através de um longo ducto pancreático que normalmente encontra o ducto hepático imediatamente antes de se esvaziar no duodeno através da papila de Vater, que é envolta pelo esfíncter de Oddi (GUYTON; HALL, 2011).

As células acinares são células epiteliais tipicamente polarizadas, cuja secreção é regulada pela mobilização de íons $\mathrm{Ca}^{2+}$. A secreção pelos ductos, por sua vez, é largamente controlada pelo AMPc. A transição entre os ácinos pancreáticos e a árvore ductal ocorre com as células centroacinares, que possuem várias características ductais e ligam as células acinares às ductais. Os ductos possuem vários segmentos baseados em seu tamanho e localização, e além de células secretoras, expressam ainda células ciliadas e produtoras de mucina. Estruturalmente, pequenos ductos intercalados unem-se e formam sequencialmente segmentos ductais intralobulares, interlobulares e interlobares (LEE et al, 2012).

\subsubsection{ENZIMAS DIGESTIVAS PANCREÁTICAS}


As enzimas digestivas pancreáticas são capazes de digerir os três principais tipos de alimentos, proteínas, carboidratos e gorduras. As mais importantes para a digestão de proteínas são a tripsina, a quimotripsnina e a carboxipolipeptidase, sendo a mais abundante delas, a tripsina. A enzima relacionada à digestão de carboidratos é a amilase pancreática e as envolvidas na digestão de gorduras são a lipase pancreática, a colesterol esterase e a fosfolipase (GUYTON; HALL, 2011).

A tripsina e a quimotripsina hidrolisam proteínas a peptídeos de tamanhos variados, sem levar à liberação de aminoácidos individuais. Por outro lado, a carboxipolipeptidase cliva alguns peptídeos a aminoácidos individuais, de forma a completar a digestão de algumas proteínas (GUYTON; HALL, 2011). Como ocorre com as proteases em geral, essa capacidade de corte das proteínas-alvo é potencialmente perigosa para as células que produzem a enzima e a solução é produzi-las em uma forma inativa, sendo importante que elas não se tornem ativadas antes de chegaram ao intestino, pois poderiam digerir o próprio pâncreas (GUYTON; HALL, 2011). Assim, quando nas células pancreáticas, as enzimas tripsina, quimotripsina e carboxipolipeptidase estão em suas formas inativas, tripsinogênio, quimotripsinogênio e procarboxipolipeptidase, respectivamente, tornando-se ativadas somente após serem secretadas no trato intestinal (GUYTON; HALL, 2011). O tripsinogênio é ativado tanto pela enzima enterocinase, secretada pela mucosa intestinal quando o quimo entra em contato com a mesma, quanto pela tripsina já formada em decorrência de uma atividade autocatalítica desta. A tripsina também ativa o quimotripsinogênio e a procarboxipolipeptidase, de forma que a inibição da tripsina quando esta ainda está no pâncreas é de fundamental importância para a inibição das demais enzimas proteolíticas pancreáticas, de sorte que as mesmas células que secretam tais enzimas nos ácinos pancreáticos secretam simultaneamente um inibidor de tripsina, que inativa a tripsina ainda nas células secretoras, nos ácinos e nos ductos do pâncreas (GUYTON; HALL, 2011).

A enzima pancreática para a digestão de carboidratos é a amilase pancreática, sendo responsável pela hidrólise de amidos, glicogênios e outros carboidratos, exceto a celulose, a dissacarídeos e trissacarídeos, principalmente. Em relação à digestão das gorduras, a lipase pancreática hidrolisa gorduras neutras em ácidos graxos e monoglicerídeos, enquanto a colesterol esterase e a fosfolipase clivam os ésteres de colesterol e os ácidos graxos de fosfolipídeos, respectivamente (GUYTON; HALL, 2011).

\subsubsection{FISIOLOGIA DA SECREÇÃO PANCREÁTICA}

\subsubsection{SECREÇÃO DE ÍONS BICARBONATO E ÁGUA}


Os íons bicarbonato e a água são secretados pelas células epiteliais dos ductos que se originam nos ácinos, principalmente nos pequenos ductos pancreáticos intralobulares e intercalados, assim como por células centroacinares (GUYTON; HALL, 2011; ISHIGURO et al, 2012, LEE et al, 2012). Uma vez estimulado, o pâncreas secreta grandes quantidades de suco pancreático em que a concentração de íons bicarbonato pode atingir $145 \mathrm{mEq} / \mathrm{l}$, valor cinco vezes maior que a sua concentração no plasma, o que confere uma grande quantidade de álcali no suco pancreático, que serve para a neutralização do ácido clorídrico que alcança o duodeno após o esvaziamento do estômago (GUYTON; HALL, 2011).

Os mecanismos celulares da secreção da solução de íons bicarbonato $\left(\mathrm{HCO}^{3-}\right)$ nos ductos pancreáticos são complexos e envolvem tanto a secreção de $\mathrm{HCO}^{3-}$, quanto à absorção de $\mathrm{Cl}^{-}$. Além disso, nesse processo participam diversos canais iônicos, bombas de prótons e transportadores localizados nas membranas basolateral e apical (luminal) das células ductais (GUYTON; HALL, 2011; ISHIGURO et al, 2012; LEE et al, 2012). Essa tarefa impõem diversos critérios para que possa ser cumprida. Em primeiro lugar, há a necessidade de que o $\mathrm{HCO}^{3-}$ concentre-se no citoplasma celular. Em segundo, uma vez secretado no espaço luminal é necessário que o $\mathrm{HCO}^{3-}$ se concentre nesse local. Por fim, enquanto absorve $\mathrm{Cl}^{-}$e secreta $\mathrm{HCO}^{3-}$, o ducto pancreático deve mediar a secreção de sais, necessária para a secreção copiosa de fluidos (LEE et al 2012).

Basicamente, o dióxido de carbono difunde-se para o interior das células ductais a partir do sangue e, sob a influência da enzima anidrase carbônica, combina-se com a água para formar ácido carbônico $\left(\mathrm{H}_{2} \mathrm{CO}_{3}\right)$. Esse ácido dissocia-se, então, em $\mathrm{H}^{+}$e $\mathrm{HCO}^{3-}$. Os íons hidrogênio $\left(\mathrm{H}^{+}\right)$formados, por sua vez, são trocados por íons $\mathrm{Na}^{+}$por meio de transporte ativo secundário na membrana basolateral (membrana sanguínea) da célula. Por outro lado, os íons bicarbonato $\left(\mathrm{HCO}^{3-}\right)$ são transportados acopladamente com os íons $\mathrm{Na}^{+}$na membrana luminal para o lúmen do ducto (GUYTON; HALL, 2011; ISHIGURO et al 2012). Ainda, essa secreção de $\mathrm{HCO}^{3-}$ para o lúmen envolve a troca deste por $\mathrm{Cl}^{-}$, de forma a ocorrer a absorção de $\mathrm{Cl}^{-}$. Simultaneamente, no entanto, o $\mathrm{Cl}^{-}$é reciclado para o lúmen ductal através do CFTR, um canal de ânions regulado por AMPc, de forma que quando essa reciclagem é acelerada pela ativação do CFTR por AMPc, a troca de $\mathrm{HCO}^{3-}$ por $\mathrm{Cl}^{-}$ocorre mais rapidamente e a secreção de $\mathrm{HCO}^{3-}$ aumenta (ISHIGURO et al 2012). Por fim, a secreção de $\mathrm{Na}^{+} \mathrm{e}$ $\mathrm{HCO}^{3-}$ para o lúmen do ducto cria um gradiente de pressão osmótica, causando o fluxo de água para o interior do ducto pancreático, formando uma solução de bicarbonato quase isotônica (GUYTON; HALL, 2011).

\subsubsection{REGULAÇÃO DA SECREÇÃO PANCREÁTICA}


Assim como a secreção gástrica, a secreção pancreática também ocorre em três fases, cefálica, gástrica e intestinal, e os ácinos e ductos pancreáticos expressam receptores para uma variedade de hormônios e neurotransmissores que regulam tal secreção (GUYTON; HALL, 2011; LEE et al 2012). Basicamente, são três os estímulos importantes na regulação da secreção exócrina do pâncreas, a acetilcolina, a colecistocinina e a secretina (Guyton; Hall, 2011), os dois últimos sendo produzidos a distância e alcançando o pâncreas pela corrente sanguínea (Lee et al., 2012). No entanto, além desses estímulos clássicos, um grande número de agentes humorais é liberado pelo pâncreas a fim de modular a sua função. A liberação de insulina pelas ilhotas de Langerhans, de somatostatina e de outros hormônios pépticos e agonistas parácrinos liberados pelas células acinares e ductais do pâncreas, tais como purinas, prostaglandinas e tripsina ativada, regulam a função das células ductais pancreáticas em estados fisiológicos e patológicos (LEE et al 2012). Ainda, a bombesina e o peptídeo intestinal vasoativo estimulam a secreção de íons bicarbonato, enquanto a substância $\mathrm{P}$, a arginina vasopressina e o ATP, inibem a sua secreção (ISHIGURO et al 2012).

A acetilcolina e a colecistocinina estimulam principalmente as células acinares do pâncreas, levando a larga produção das enzimas digestivas pancreáticas e pequenas quantidades de água e eletrólitos, mas também podem estimular ou potencializar a secreção ductal. Em contrapartida, a secretina promove a secreção de grandes volumes de solução de bicarbonato de sódio pelo epitélio do ducto pancreático; no entanto, os estímulos da secreção pancreática agem simultaneamente, de forma que a secreção total é maior do que a soma causada por parte de cada um deles separadamente, havendo um sinergismo entre as vias de sinalização do AMPc (secreção ductal) e do $\mathrm{Ca}^{2+}$ (secreção acinar) (GUYTON; HALL, 2011; LEE et al 2012).

Durante a fase cefálica da secreção pancreática, quantidades moderadas de enzimas digestivas são secretadas nos ácinos pancreáticos, correspondendo a cerca $20 \%$ da secreção enzimática total após uma refeição. Tal fase é regulada pelos mesmos sinais nervosos que controlam a fase cefálica da secreção gástrica, causando a liberação de acetilcolina pelo nervo vago no pâncreas (GUYTON; HALL, 2011). Essa acetilcolina age em receptores muscarínicos tipo 1 e 3 (M1 e M3), sobretudo M3, nos ácinos, promovendo o aumento da concentração intracelular de íons $\mathrm{Ca}^{2+}$. Os ductos pancreáticos, também exprimem tais receptores muscarínicos, de forma que a estimulação colinérgica além de promover a secreção enzimática, aumenta a secreção ductal estimulada pela secretina (LEE et al 2012).

A estimulação nervosa da secreção de enzimas pancreáticas prossegue durante a fase gástrica, contribuindo com 5 a 10\% do total de enzimas pancreáticas secretadas após uma refeição; no entanto, tanto na fase cefálica como na gástrica, 
pouco dessa secreção flui imediatamente através dos ductos pancreáticos para o duodeno, pois somente pequenas quantidades de água e eletrólitos (secreção líquida) são secretadas juntamente com as enzimas (GUYTON; HALL, 2011).

A fase intestinal da secreção pancreática inicia-se quando o quimo entra no intestino, uma vez que este estimula a liberação de colecistocinina e secretina pelas mucosas do duodeno e do jejuno (GUYTON; HALL, 2011). A colecistocinina é um polipeptídeo com 33 aminoácidos liberado pelas chamadas células I, na mucosa duodenal e jejunal, em decorrência de produtos da digestão parcial de proteínas, como proteoses e peptonas, e de ácidos graxos de cadeia longa no quimo que alcança o intestino. Ela chega ao pâncreas pela corrente sanguínea e provoca, principalmente, a secreção de enzimas digestivas pancreáticas pelas células acinares, apesar de poder pronunciar o efeito da secretina nas células ductais (GUYTON; HALL, 2011; CHANDRA; LIDDLE et al 2009; LEE et al 2012). O efeito da colecistocinina nos ácinos é semelhante ao efeito promovido pela estimulação vagal, sendo, entretanto, mais pronunciado, respondendo por cerca de 70 a $80 \%$ da secreção total das enzimas digestivas após uma refeição (GUYTON; HALL, 2011).

O mecanismo de ação da colecistocinina nas células acinares é controverso, mas sugere-se que ela atue por dois possíveis mecanismos. Primeiro, interação da colecistocinina aos seus receptores nos ácinos pancreáticos, com o consequente aumento dos níveis intracelulares de $\mathrm{Ca}^{2+}$ e exocitose das enzimas. Segundo, efeito indireto via estimulação vagal, devido à ligação da colecistocinina a receptores sensíveis à capsaicina do tipo $\mathrm{C}$, presentes em fibras aferentes do nervo vago, o que resulta na liberação de acetilcolina pelas terminações nervosas vagais eferentes (LEE et al 2012).

A secretina, em contrapartida, estimula o pâncreas a secretar grandes quantidades de líquido contendo elevadas concentrações de íons bicarbonato. Ela é um polipeptídeo com 27 aminoácidos, em sua forma inativa, a pró-secretina, nas chamadas células $\mathrm{S}$ no duodeno e jejuno. $\mathrm{O}$ pH intraduodenal inferior a 4,5, resultante da entrada do quimo ácido proveniente do estômago no intestino, promove a ativação e liberação da secretina da mucosa duodenal para o sangue (GUYTON; HALL, 2011; LEE et al 2012). A sua liberação aumenta bastante quando o pH cai para 3,0, levando à secreção abundante de suco pancreático com grande quantidades de bicarbonato de sódio, o que é de enorme importância para a proteção da mucosa intestinal, pois a neutralização do ácido gástrico é essencial para evitar o desenvolvimento de úlceras duodenais. Essa neutralização ocorre pela reação entre o ácido clorídrico $(\mathrm{HCl})$ com o bicarbonato de sódio $\left(\mathrm{NaHCO}_{3}\right)$, com consequente formação de cloreto de sódio $(\mathrm{NaCl})$ e ácido carbônico $\left(\mathrm{H}_{2} \mathrm{CO}_{3}\right)$, o qual se dissocia imediatamente em dióxido de carbono $\left(\mathrm{CO}_{2}\right)$ e água $\left(\mathrm{H}_{2} \mathrm{O}\right)$. $\mathrm{O}$ dióxido de carbono é transferido, então, para o sangue e expirado pelos pulmões, deixando uma solução neutra de $\mathrm{NaCl}$ no duodeno (GUYTON; HALL, 2011). 


\subsection{FÍGADO E SECREC̣ÃO BILIAR}

O fígado é o maior órgão do corpo e possui uma habilidade única em modificar seu volume dependendo do estado fisiológico do indivíduo (YOKOYAMA et al 2007). É responsável por várias funções vitais e pela manutenção da homeostasia corporal, como regulação do metabolismo de diversos nutrientes, papel imunológico, síntese proteica e de outras moléculas, armazenamento de vitaminas e ferro, degradação hormonal e a inativação e excreção de fármacos e toxinas (CORREA; NATHANSON, 2007). Por outro lado, alguns fatores podem afetar negativamente a capacidade de autorregeneração hepática, tais como diabetes, má nutrição, etilismo, obstruções biliares, infecções virais, idade e gênero do indivíduo (YOKOYAMA et al 2007).

O fígado compreende um sistema de captação e exportações da bile e de seus compostos (TRAUNER et al 2005), sendo a secreção biliar uma das principais funções desempenhadas por este órgão, representando sua função exócrina (CORREA; NATHANSON, 2007). A secreção biliar serve, portanto, como uma importante via excretora para diversos endo e xenobióticos, tais como a bilirrubina, produtos lipídicos bacterianos (endotoxinas) e diversos mediadores inflamatórios (ARRESE; TRAUNER, 2003; RESHETNYAK, 2015). Além disso, a bile é responsável pela homeostase do metabolismo lipídico, em particular o metabolismo do colesterol, e é essencial para absorção de lipídios no lúmen intestinal (ARRESE; TRAUNER, 2003; RESHETNYAK, 2015).

A bile, em sua constituição, possui quase todos os compostos do organismo: proteínas, principalmente globulinas; lipídios, como o colesterol e fosfolipídios (lectinas); carboidratos, com pequenas quantidades de diglicerídeos; sais minerais, similar ao conteúdo eletrolítico do plasma; e vitaminas (RESHETNYAK, 2015). Dentre esses constituintes, as substâncias mais abundantemente secretadas na bile são os sais biliares $(67 \%)$, fosfolipídios (22\%), proteínas $(4,5 \%)$, colesterol (4\%)e bilirrubina (0,3\%) (RESHETNYAK, 2015).

A bile, com grande quantidade de sais biliares e colesterol, é inicialmente secretada pelos hepatócitos nos canalículos biliares, os quais desembocam nos ductos biliares terminais, onde uma secreção hepática aquosa de íons sódio e bicarbonato é acrescentada à bile, pelos colangiócitos (TRAUNER et al., 2005; RESHETNYAK, 2015).

O processo de secreção da bile pelos hepatócitos é dependente de ATP, isto é, os componentes da bile são secretados por transporte ativo, seguido pelo movimento passivo de água (ARRESE; TRAUNER, 2003; TRAUNER et al., 2005). Além disso, a secreção biliar depende da polarização dos hepatócitos, que consiste em um domínio basocelular voltado para a circulação e um domínio apical que forma o canalículo biliar, ambos contendo diferentes proteínas de transporte na membra- 
na, importantes para a formação e secreção da bile (ARRESE; TRAUNER, 2003; RESHETNYAK, 2015). De forma semelhante aos hepatócitos, os colangiócitos também possuem transportadores de membrana essenciais à formação da secreção biliar (ARRESE; TRAUNER, 2003).

Através dos ductos biliares terminais, a secreção biliar flui até o ducto biliar comum, de onde alcança diretamente o intestino. Continuamente a bile é secretada pelas células hepáticas, entretanto a maior parte é armazenada na vesícula biliar até que ele seja necessária no duodeno. Embora a água e a maioria dos eletrólitos sejam continuamente absorvidos pela mucosa da vesícula biliar, concentrando a bile, outros componentes como sais biliares, colesterol, lectina e a bilirrubina, não são reabsorvidos (GUYTON; HALL, 2011).

A maioria dos compostos biliares secretados, tais como ácidos biliares, bilirrubina e colesterol, é alvo de intensa circulação entero-hepática, ou seja, são reabsorvidos no intestino delgado, alcançam o fígado e são secretados novamente na bile. Tal processo pode ocorrer repetidas vezes até serem excretados nas fezes. Além disso, os compostos biliares também podem ser reabsorvidos pelos colangiócitos no epitélio ductal, retornando para os hepatócitos, bem como reabsorvidos no túbulo renal proximal, também retornando aos hepatócitos, impedindo a excreção de ácidos biliares na urina (TRAUNER et al., 2005).

Quando o alimento começa a ser digerido na porção superior do trato gastro-intestinal a vesícula biliar começa a se esvaziar, principalmente quando alimentos gordurosos chegam ao duodeno, aproximadamente 30 minutos após a refeição. A vesícula esvazia, pois sua parede que é constituída de músculo liso apresenta contrações rítmicas, entretanto para o seu esvaziamento, ocorre o relaxamento do esfíncter de Oddi que se localiza na entrada do ducto biliar comum ao duodeno (GUYTON; HALL, 2011).

Alimentos gordurosos na mucosa duodenal constituem os principais responsáveis pelo estímulo de colecistocinina na corrente sanguínea. O hormônio colecistocinina é o estímulo mais potente para o esvaziamento da vesícula, enquanto que o sistema nervoso entérico e vagal são estímulos mais fracos. O hormônio secretina também aumenta a secreção da bile, mas geralmente algumas horas após a refeição (GUYTON; HALL, 2011).

\subsubsection{BILIRRUBINA}

A bilirrubina não conjugada é um pigmento tetrapirrol formado pelo catabolismo de hemoglobina (Ostrow, 1986), produzida no sistema reticuloendotelial do baço, fígado e medula óssea, predominantemente a partir da degradação do heme, ou seja, da destruição de eritrócitos. Embora citocromos e mioglobina contribuam com uma pequena quantidade (Butcher, 2003), a bilirrubina se torna 
clinicamente importante quando os processos de excreção hepática estão comprometidos (Ostrow, 1986).

A coloração da hemoglobina é vermelha e sua estrutura é cíclica. Através de um sistema enzimático oxidante sua estrutura é transformada em linear originando a biliverdina que possui coloração verde. A biliverdina por sua vez é reduzida à bilirrubina, a qual possui coloração amarelada (Chowdhuryet al., 2007; Kuntz; Kuntz, 2006b; Guyton; Hall, 2011).

A conversão de bilirrubina não conjugada a diglicuronídeo ou monoglucuronídeo de bilirrubina, através de esterificação de ambos ou de um dos grupos carboxil do ácido propiônico, é um processo crítico para excreção de bilirrubina (Chowdhuryet al., 2007), pois a mesma é insolúvel em água e difundida através de membranas. A solubilização da bilirrubina não conjugada ocorre através de fortes ligações com a albumina e na bile, pelo estabelecimento de interações fracas com os sais biliares, micelas mistas e vesículas lipídicas. Por isso, a excreção renal da bilirrubina não conjugada é limitada, devido à ligação com a albumina, razão pela qual é eliminada, sobretudo pelo fígado (Butcher, 2003; Brites; Tiribelli, 2001). Assim, para que haja uma excreção da bilirrubina pela bile é indispensável a sua biotransformação em conjugadas.

Após a clivagem de albumina, a bilirrubina é conjugada com glicuronídeo, utilizando a enzima UDP glicuronil-transferase no retículo endoplasmático do hepatócito. A bilirrubina conjugada é solúvel em água e é excretada ativamente através da membrana canalicular em canalículo biliar, usando uma bomba dependente de ATP. A maioria é, então, excretado nas fezes, mas algumas desconjugações ocorrem no intestino e uma pequena quantidade deste urobilinogênio é reabsorvido e excretado na urina (Butcher, 2003). A bilirrubina é um dos vários substratos endógenos e exógenos, cuja conjugação com ácido glicurônico é mediada por uma ou mais isoformas de uridinadifosfato glicuronosiltransferases (UGTs). As UGTs são enzimas que catalisam a transferência do radical ácido glicurônico de UDP-glicurônico para os substratos agliconas, formando produtos polares e, geralmente, menos bioreativos (Chowdhury et al., 2007).

As causas mais comuns de icterícia envolvem um defeito no metabolismo da bilirrubina ou sua excreção. No entanto, o aumento da renovação das células vermelhas, como na hemólise, pode saturar o sistema responsável pela eliminação da bilirrubina, resultando em icterícia (Butcher, 2003). Na icterícia, a pele fica amarelada devido o acúmulo de bilirrubina no plasma (Guyton; Hall, 2011).

\subsubsection{SAIS BILIARES}

Os sais biliares, principais constituintes da bile, são sintetizados no fígado a partir do colesterol, constituindo-se como a principal via de catabolismo desse composto nos seres humanos (Chiang et al., 2009; Reshetnyak, 2015). O coleste- 
rol é primeiramente convertido em ácido cólico ou ácido quenodesoxicólico, os quais se combina principalmente com a glicina ou taurina para formar os ácidos biliares glico e tauroconjugados, respectivamente. Os sais desses ácidos são, então, secretados na bile (Reshetnyak, 2015). A característica anfipática dos sais biliares fornece à bile importante função no metabolismo e absorção de lipídios no intestino delgado, uma vez que essas moléculas servem como detergentes fisiológicos, emulsificando as gorduras (Chiang et al., 2009; Kroll, 2012). A absorção e o transporte de nutrientes e vitaminas no intestino também são facilitados pelos sais biliares (Chiang et al., 2009). Os ácidos biliares funcionam, ainda, como moléculas de sinalização e agentes inflamatórios, ativando receptores nucleares e vias de sinalização celular que regulam o metabolismo de glicose, de lipídeos e o metabolismo energético (Chiang, 2009; Kroll, 2012).

A síntese dos ácidos biliares pode ocorrer por uma via clássica, neutra, ou uma via alternativa, ácida (Reshetnyak, 2015). Ambas consistem em conversões enzimáticas sucessivas, onde o processo é iniciado classicamente pela enzima colesterol-7 $\alpha$-hidroxilase, seguido pela oxidação dos intermediários formados pela ação dessa enzima, no retículo endoplasmático liso, e pelo encurtamento da cadeia lateral nas mitocôndrias. Os produtos formados por esses passos são chamados de ácidos biliares primários e o fígado é o único órgão que tem as 14 enzimas necessárias para a síntese dos dois principais ácidos biliares primários encontrados em humanos, o ácido cólico e o ácido quenodesoxicólico. O passo terminal da síntese dos ácidos biliares envolve a conjugação dos mesmos com aminoácidos, geralmente a glicina ou a taurina, o que diminui a sua toxicidade e aumenta a sua anfipaticidade e solubilidade, o que os torna impermeáveis à membrana celular e beneficia a secreção desses sais na bile (Russel, 2003; Reshetnyak, 2015). A partir dos ácidos primários, os ácidos biliares secundários (litocólico e deoxicólico) são formados, o que resulta na atividade de micro-organismos anaeróbios intestinais no íleo, ceco e cólon. Os ácidos biliares secundários tornam-se parcialmente absorvidos no intestino e, após reconjugação com glicina ou taurina no fígado, são excretados para o canalículo. A bile contém, portanto, uma mistura de ácidos biliares primários e secundários (Kuntz; Kuntz, 2006c). Os ácidos biliares terciários (sulfolitocólico e ursodesoxicólico) são formadas no fígado e intestino, e são derivados a partir dos ácidos biliares secundários que passam pela circulação ênterohepática, formando uma nova estrutura química (Kuntz; Kuntz, 2006c). A síntese de ácido biliar e fluxo biliar diminui acentuadamente durante o envelhecimento (Bertolotti et al., 2007) e que os ácidos biliares e seus receptores são alvos terapêuticos para o desenvolvimento de drogas no tratamento de doenças esteatohepáticas e colestáticas, diabetes, obesidade e síndrome metabólica (Chiang, 2009). 
Após cada refeição, a vesícula biliar libera o conteúdo de sais biliares no intestino, onde se misturam com quimo proveniente do estômago e participam do processo de metabolismo e absorção das gorduras (Reshetnyak, 2015). Aproximadamente $95 \%$ desses ácidos biliares são reabsorvidos e retornam ao fígado através da circulação portal, enquanto que os não reabsorvidos são excretados nas fezes (Guyton; Hall, 2011). Na porção intestinal da circulação ênterohepática, os ácidos biliares são reabsorvidos tanto por processo passivo como por processo ativo, este limitado ao íleo e responsável pela maior reabsorção dos ácidos biliares por meio do transportador de ácido biliar dependente de sódio (ASBT) (Reshetnyak, 2015; Kullak-Ublick; Stieger; Meier, 2004). O passo final da circulação ênterohepática é a captação dos ácidos biliares presentes na circulação porta, que estão associados à albumina ou a liproteínas de baixa densidade (HDL), pelos hepatócitos. Essa captação é mediada por um sistema de transporte de membrana específico, que compreende polipeptídeos e glicoproteínas com fortes afinidades para os ácidos biliares, tais como o polipeptídeo co-transportador sódio-dependente de taurucolato (NTCP). Além disso, os hepatócitos contêm outras proteínas transportadores independentes de sódio, incluindo os polipeptídeos transportadores de ânions orgânicos (OATPs) (Reshetnyak, 2015; Kullak-Ublick; Stieger; Meier, 2004).

\subsection{INTESTINOS E SECREÇÕES ENTÉRICAS}

O intestino consiste em um longo órgão de absorção, cujo epitélio é constituído por vilosidades, dentre as quais, encontram-se as criptas de Lieberkühn. Tais epitélios, tanto de criptas como de vilos, são formados por células caliciformes, responsáveis pela secreção de muco que lubrifica e protege as superfícies intestinais, e também pelos enterócitos que, nas criptas, secretam grandes quantidades de água e eletrólitos, enquanto que nas vilosidades adjacentes, absorvem água, eletrólitos e produtos finais da digestão. Em geral, o epitélio intestinal separa toxinas e antígenos bacterianos, altamente concentrados no lúmen intestinal, dos tecidos linfoides associados ao trato intestinal (Kagnoff \& Eckmann, 1997), enquanto extremamente importante no processo digestivo. Dessa maneira, tal superfície representa uma importante barreira entre os agentes deletérios presentes no lúmen e o organismo (Sturm et al., 1999). Além disso, o intestino é preparado para a eliminação de certos ácidos orgânicos, bases e compostos neutros, de acordo com a sua afinidade, para os sistemas de transporte intestinal (Wagner et al., 2001).

O duodeno é um segmento principal do trato gastrointestinal (TGI) devido ao seu posicionamento estratégico entre o piloro e ducto pancreático. A mucosa duodenal está exposta a produtos químicos endógenos e exógenos, incluindo ácidos, $\mathrm{CO}_{2}$, ácidos biliares e nutrientes. As respostas fisiológicas, tais como a 
secreção, a digestão, a absorção e a motilidade dependem da atuação de sensores químicos presentes na mucosa (Yasutada; Jonathan, 2011).

Os intestinos delgado e grosso são protegidos por muco, constituído principalmente por mucina MUC2, entretanto, as propriedades do muco nestes dois locais são distintas. O muco ileal tem apenas uma camada, não está aderido ao epitélio e é permeável a bactérias, diferente do muco no intestino grosso (Johansson et al., 2013).

As secreções intestinais resultam predominante da secreção ativa dos íons cloreto nas criptas e bicarbonato. A secreção destes íons gera uma diferença de potencial elétrico que se constitui na força para a secreção de íons sódio. A secreção dos eletrólitos causa fluxo osmótico de água. Tais processos secretores quais estão sob controle de vários mediadores intracelulares como adenosina monofosfato cíclico (AMPc), guanidina monofosfato cíclico (GMPc), cálcio, calmodulina, e metabólitos de fosfatidilinositol. As respostas secretoras dependentes de AMPc são prolongadas, enquanto as dependentes de cálcio são transitórias e de menor magnitude (Banks; Farthing, 2002).

A produção dessas secreções é importante para o processamento do quimo, o qual será o substrato para a digestão e absorção. Os estímulos osmóticos e neurais desencadeiam a liberação hormonal, promovendo uma absorção normal, em que macromoléculas são progressivamente hidrolisadas. Impulsos aferentes vagais mediados por 5-hidroxitriptamina, peptídeo intestinal vasoativo e substância P são os principais agentes da estimulação secretória (Wapnir; Teichberg, 2002).

\subsection{INTESTINO DELGADO}

A digestão enzimática ocorre dentro do intestino delgado, enquanto a desagregação mecânica ocorre no estômago. A fim de aumentar a área da superfície do intestino delgado, e ter uma maior absorção, o epitélio intestinal é dividido em centenas de milhares de projeções digitiformes, vilosidades, para dentro do lúmen (Mazzucchelli; Maurrey, 2003).

No início da submucosa duodenal existe um grande número de glândulas denominadas glândulas de Brunner, que secretam um fluido alcalino composto de Mucina (Muc-6) que protege o epitélio duodenal por contrabalancearem o ácido produzido no estômago (Costa-Pinho et al., 2011). Estímulos táteis e vagais, além de hormônios gastrointestinais como a secretina podem aumentar a produção deste muco alcalino. Ainda, esta secreção contém grande quantidade de íons bicarbonato, que se somam aos íons bicarbonatos da secreção pancreática e da bile, auxiliando na neutralização do $\mathrm{pH}$ do quimo. A inibição desta glândula ocorre por estimulação simpática, portanto, sugere-se que tal estimulação em pessoas tensas seja responsável pelo aparecimento de úlceras pépticas, haja vista uma desproteção do bulbo duodenal (Guyton; Hall, 2011). 
A lâmina própria, rica em células linfoides, forma a parte central de cada uma das vilosidades, onde estão presentes numerosas criptas de Lieberkuhn (Krause, 2000). Estas são formadas por dois tipos de células epiteliais, as células caliciformes que secretam muco para proteger e lubrificar as superfícies intestinais e também os enterócitos, células que nas criptas secretam água e eletrólitos, e nas vilosidades, reabsorvem água, eletrólitos e produtos finais da digestão (Guyton; Hall, 2011). Logo após as secreções, ocorre a reabsorção nas vilosidades. É esta circulação de secreção e reabsorção que proporciona um meio aquoso para a reabsorção de substâncias que entram em contato com as vilosidades intestinais (Guyton; Hall, 2011). Assim, a principal função do intestino delgado é a digestão e absorção de nutrientes. Nesse processo, o papel da motilidade intestinal consiste em promover um contato entre os produtos alimentares e as enzimas digestivas, contribuindo para absorção pelas células presentes ao longo do intestino (Freeman; Thomson, 2005).

Mensageiros químicos também podem regular as ações e o controle do trato gastrointestinal (Rodrigues; Fonseca; Neves, 2005). Dentre estes incluem a colecistocinina (CCK) e secretina. Estes mediadores são liberados endogenamente pelo estômago e intestino. As ações fisiológicas da CCK consistem na estimulação da secreção pancreática, contração da vesícula biliar, regulamento do esvaziamento gástrico, indução da saciedade. Portanto, CCK regula a ingestão, digestão e absorção de nutrientes (Liddle, 1997). A secretina, por sua vez, tem sido identificada como hormônio regulador da secreção exócrina de fluido e bicarbonato, secreção gástrica ácida e motilidade gástrica (William; Ta-Min, 2003).

As enzimas secretadas no intestino delgado são sacarase, maltase, isomaltase e lactase para a dissolução de dissacarídeos em monossacarídeos, produto final da digestão dos carboidratos. Peptidases são responsáveis pela digestão final das proteínas em pequenos aminoácidos, e lipases, pela a degradação final de gorduras (Guyton; Hall, 2011).

\subsubsection{INTESTINO GROSSO}

A função do intestino grosso consiste na absorção da água dos nutrientes ingeridos após a sua passagem através do intestino delgado. O intestino grosso é também responsável por ajudar a manter o equilíbrio de sódio e outros minerais no organismo. Seu epitélio é constituído de três tipos de células: caliciformes produtoras de muco, enterendócrinas e colunares, que também são referidos como colonócitos (Worrell et al., 2003).

$\mathrm{O}$ intestino grosso, assim como o intestino delgado, secreta grande quantidade de muco, desde a válvula ileocecal até o ânus. Entretanto, diferente do intestino delgado, o intestino grosso não possui vilosidades, apenas e muitas glândulas de Lieberkühn. $\mathrm{O}$ muco do intestino grosso protege a parede intestinal contra esco- 
riações, além de proporcionar um meio aderente para manter as sustâncias fecais úmidas. Além disso, protege a parede intestinal da atividade bacteriana local (Guyton; Hall, 2011). No cólon transverso, a secreção de muco é mais abundante ainda. O muco do cólon é formado por 2 camadas. Uma delas é formada por células caliciformes secretoras e possui uma morfologia estratificada, permanecendo ligada ao epitélio e sendo convertida em externa (Johansson et al., 2011)

A regulação homeostática da função do cólon é principalmente dirigida para a inibição da via de absorção ou a estimulação da via secretora. A regulação da secreção ocorre através de mecanismos parácrinos, endócrinos, autócrinos e neuroendócrinos. Embora um grande número de agentes terem demonstrado influenciar a secreção de $\mathrm{Cl}^{-}$e $\mathrm{K}^{+}$, a maioria destes o fazem por efeitos sobre o AMPc intracelular, GMPc, $\mathrm{Ca}^{2+}$ ou PKC. (Worrell et al., 2003)

Os dois agonistas fisiológicos mais importantes são acetilcolina (ACh) e polipeptídeo intestinal vasoactivo (VIP), o que leva a um aumento intracelular de $\mathrm{Ca}^{2+}$ e AMPc, respectivamente (Worrell et al., 2003).

Em contraste com os processos de absorção, os processos secretórios são mais regulados. Perturbações patológicas do equilíbrio entre a absorção e processos secretórios geralmente envolvem um aumento na secreção e, assim, a diarreia (Worrell et al., 2003).

\subsection{A INTERFERÊNCIA DE FÁRMACOS NAS SECREÇÕ̃ES SALIVARES E GASTRINTESTINAIS}

A influência dos fármacos nas secreções salivares e gastrintestinais relaciona-se aos seus efeitos terapêuticos ou adversos. Por exemplo, em casos de úlceras pépticas, refluxo gastroesofágico e lesões causadas por anti-inflamatórios não-esteroidais podem ser utilizados fármacos que neutralizam ou inibam a secreção de ácido gástrico, promovendo uma melhoria nos sintomas e no quadro patológico das doenças. Entretanto, alguns medicamentos também podem contribuir para o aparecimento de reações adversas, que podem envolver qualquer sistema de órgãos do corpo, incluindo as secreções salivares, induzindo a xerostomia, hipersalivação e sialolitíase (Vinayak et al., 2013).

A xerostomia é a sensação subjetiva de boca seca, um sintoma que pode ou não ser acompanhado de hiposalivação, uma diminuição do fluxo salivar (Napeñas; Brennan; Fox, 2009). Em contrapartida, a hipersalivação consiste na produção excessiva de saliva (Lakraj; Mohimi; Jabbari, 2013). Por sua vez, a sialolitíase é definida como a formação ou a presença de cálculos nas glândulas salivares (Andretta et al., 2005).

Entre os fármacos que reduzem a acidez intragástrica, destacam-se os antiácidos, antagonistas dos receptores $\mathrm{H}_{2}$, inibidores da bomba de prótons e antago- 
nistas muscarínicos. Os antiácidos, tais como bicarbonato de sódio, bicarbonato de cálcio, hidróxido de magnésico e hidróxido de alumínio, consistem em bases fracas que neutralizam o meio ácido do estômago, formando sal e água. Apesar do seu principal mecanismo seja a diminuição da acidez, essas preparações também aumentam a produção de prostaglandinas, as quais protegem a mucosa gástrica (Pleuvry, 2009; Katzung; Masters; Trevor, 2014).

Quanto aos antagonistas dos receptores $\mathrm{H}_{2}$, como a cimetidina, sabe-se que estes exibem inibição competitiva nos receptores $\mathrm{H}_{2}$ das células parietais e reduzem a secreção ácida estimulada pela histamina e pela gastrina. Consequentemente, também há a supressão da secreção de pepsina (Rang et al., 2012; Katzung; Masters; Trevor, 2014). Os inibidores da bomba de prótons, como o omeprazol, consistem em pró-fármacos inativos que inibem a secreção tanto em jejum quanto estimulada, uma vez que atuam na via final desse processo, a bomba de prótons. Estes fármacos se ligam covalentemente com o grupo sulfidril de cisteína localizado no domínio extracelular de $\mathrm{H}^{+} / \mathrm{K}^{+}$-ATPase, sendo esta associação essencial para a inibição irreversível da bomba de prótons (Rang et al., 2012; Pleuvry, 2009). Antagonistas muscarínicos são utilizados raramente na redução da secreção gástrica, uma vez que provocam efeitos adversos, como xerostomia e midríase. Possuem um mecanismo de ação associado à redução dos efeitos da acetilcolina, liberada por um estímulo vagal, nos receptores muscarínicos. Pirenzepina, um antagonista seletivo do receptor M1, pode reduzir a secreção ácida cerca de $40 \%$. Acredita-se que este fármaco previna a estimulação vagal pós-sináptica nas células parietais (Pleuvry, 2009) (Figura 19.5).

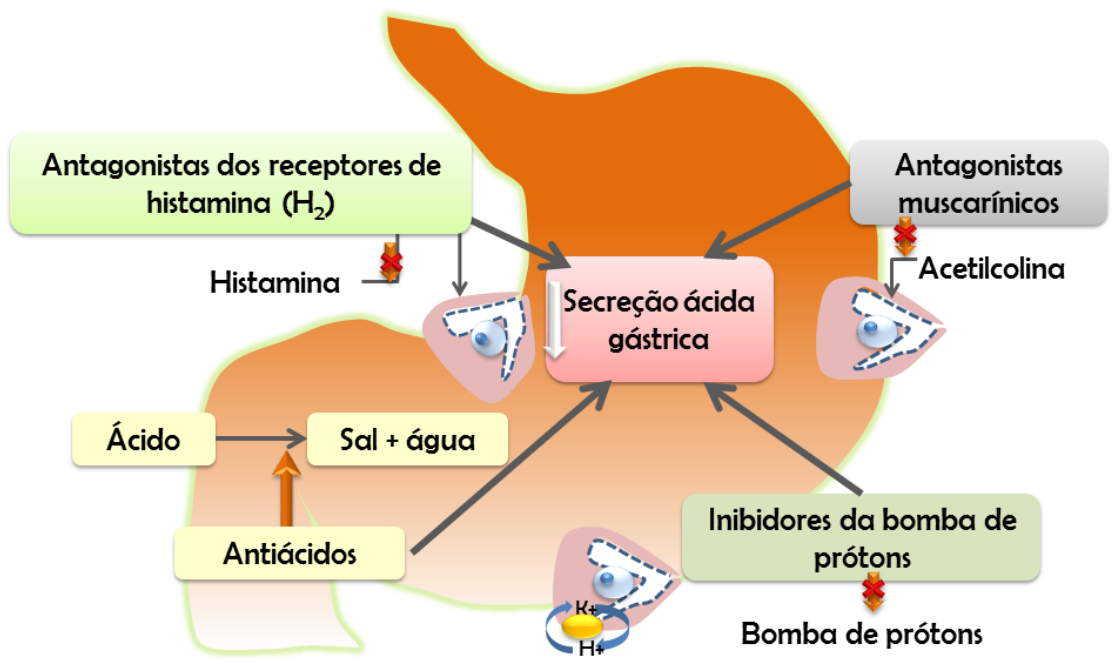


Figura 19.5 - Mecanismo de ação dos fármacos que reduzem a secreção gástrica.

A respeito das secreções salivares, sabe-se que estas são produzidas por glândulas controladas pelo sistema nervoso autônomo e afetadas por uma variedade de fármacos, induzindo xerostomia ou hipersalivação. No que concerne à xerostomia, esta consiste em um sintoma oral desconfortante e potencialmente prejudicial, geralmente provocada por uma diminuição da taxa de secreção de saliva pela hipofunção da glândula salivar. Possui etiologia relacionada aos hábitos, como tabagismo e alcoolismo, além de uma ampla variedade de fármacos, os quais aumentam a suscetibilidade da condição (Sreebny; Schwartz, 1997). Cerca de 70\% dos adultos que estão sendo submetidos a tratamentos farmacológicos podem desenvolver a xerostomia como efeito adverso (Ciancio, 2004). Dentre estes, destacam-se os indivíduos que tomam antidepressivos tricíclicos, anticolinérgicos, $\alpha$ - e $\beta$-bloqueadores, diuréticos, antipsicóticos, anti-histamínicos e anti-hipertensivos (Scully, 2003; Miranda-Rius et al., 2015).

Os antidepressivos tricíclicos (ADT) exercem seus efeitos através de mecanismos noradrenérgicos, histamínicos e colinérgicos, culminando no aparecimento de xerostomia ao bloquear os receptores muscarínicos M3. Choi et al. (2006) observaram que a desipramina inibe diretamente a bomba de $\mathrm{Na}^{+} / \mathrm{H}^{+}$, a qual é importante para a secreção salivar na glândula submandibular em humanos. Ao utilizar glândulas parótidas de ratos, Silva et al. (2009) revelaram que a fluoxetina e venlafaxina reduziu o fluxo salivar estimular e aumentou o volume celular, resultando em hipertrofia glandular com fluoxetina e em ação anticolinérgica mais pronunciada quando administrada por 60 dias.

Agentes antimuscarínicos podem atuar em algumas condições sistêmicas, como incontinência urinária e bexiga hiperativa. Entretanto, a maioria desses fármacos não possui seletividade para os receptores, induzindo o aparecimento de efeitos adversos, como a xerostomia (Scully, 2003). Quanto aos antagonistas adrenérgicos relacionados também aos problemas urinários, destacam-se os antagonistas seletivos para $\alpha_{1}$, como prazosina, silosina, tansulosina. Esses fármacos, além de promoverem o relaxamento das células musculares da próstata e uretra, agem em receptores pós-sinápticos $\alpha_{1}$ presentes em glândulas salivares, causando a xerostomia (Scully, 2003; Rang et al., 2012). De fato, Ynai-Inamura et al. (2012) mostraram que a tansulosina inibiu a secreção salivar, induzida por fenilefrina, de maneira dose-dependente.

Os diuréticos de alça e os poupadores de potássio se destacam na indução da xerostomia, visto que seus mecanismos de ação incluem a maior excreção de eletrólitos como $\mathrm{Na}^{+}, \mathrm{Cl}^{-}$e $\mathrm{K}^{+}$, os quais participam do processo da produção salivar (Nederfors; Nauntofte; Twetman, 2004). 
O tratamento ao longo prazo com antipsicóticos, como fenotiazinas, são comumente associados com a xerostomia, uma vez que interferem nos sistemas dopaminérgico, noradrenérgico e histamínico (Rang et al., 2012).

Classicamente, os anti-histamínicos são utilizados em reações alérgicas menores ou sintomas da gripe. Atuam na inibição dos receptores de histamina H1 e podem causar xerostomia, por mecanismos ainda não totalmente elucidados. No entanto, sugere-se que os receptores histaminérgicos estão envolvidos na sinalização de cálcio funcional das glândulas salivares humanas (Kim et al., 2009). Atualmente, a explicação mais aceita está relacionada ao efeito antimuscarínico do anti-histamínico (Liu et al, 2006).

Os anti-hipertensivos, como os diuréticos, beta-bloqueadores, agonistas $\alpha_{2} \mathrm{e}$ bloqueadores dos canais de cálcio, também podem estar relacionados à xerostomia. Prasanthi, Kannan, Patil (2014) revelaram que pacientes utilizando diuréticos obtiveram uma diminuição da taxa de fluido salivar, $\mathrm{pH}$, capacidade de tam-

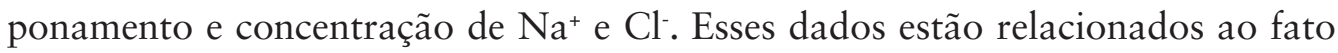
dos diuréticos bloquearem o sistema de co-transporte de eletrólitos. Tanna et al. (2010) demonstraram que a xerostomia consistiu em um efeito adverso presente em pacientes utilizando agonista $\alpha_{2}$. Em relação aos beta-bloqueadores, Croog et al. (1994) observaram que pacientes utilizando atenolol também tiveram sintomas de xerostomia. Quanto aos bloqueadores dos canais de cálcio, como nifedipina, diltiazem e verapamil, Hattori, Wang (2007) demonstraram que os canais de cálcio estão envolvidos na secreção salivar. Assim, esses fármacos bloqueiam esses canais e inibem a secreção de água destilada, culminando na diminuição da produção de saliva.

Exemplos de classes farmacológicas que podem estar envolvidas na redução da secreção salivar estão listadas na Tabela 19.1.

O aumento da secreção salivar (hipersalivação) ocorre por efeitos colinérgicos de fármacos que podem atuar no sistema parassimpático, ligando-se diretamente aos receptores ou agindo em inibidores da colinesterase (Vinayak et al., 2013). Agonistas muscarínicos diretos, como pilocarpina, arecolina, betanecol podem aumentar o tônus colinérgicos e induzir sialorreia (Freudenreich, 2005; Gorsky et al., 2004).

Os psicóticos de primeira geração, como haloperidol e flufenazina, e os de segunda geração, como clozapina, risperidona e reserpina, podem promover hipersalivação pelo bloqueio de receptores adrenérgicos $a_{2}$ ou diminuição de noradrenalina ou o antagonismo direto dos receptores muscarínicos M3 e M4 (Miranda-Rius et al., 2015). As classes farmacológicas que estão relacionadas ao aparecimento da hipersalivação estão listadas na Tabela 19.1. 
Tabela 19.1 - Fármacos relacionados à xerostomia e à hipersalivação

\begin{tabular}{|c|l|l|}
\hline Classes farmacológicas & \multicolumn{1}{|c|}{ Fármacos } & Efeito farmacológico \\
\hline Antidepressivos & Amitriptilina & Xerostomia \\
\hline Anticolinérgicos & Atropina, Pirenzepina & Xerostomia \\
\hline An-bloqueadores & Tansulozina, Prazosina & Xerostomia \\
\hline Diuréticos & Fenotiazina & Xerostomia \\
\hline Anti-hipertensivos & Furosemida & Xerostomia \\
\hline Broncodilatadores & Atenolol, nifedipina & Xerostomia \\
\hline Relaxantes musculares & Tiotrópio & Xerostomia \\
\hline Benzodiazepínicos, hipnóticos, & Morfina, diazepam & Xerostomia \\
\hline opioides e drogas de abuso & & Xerostomia \\
\hline Inibidores da bomba de prótons & Omeprazol & Hipersalivaç̃a \\
\hline Agonistas muscarínicos & Pilocarpina, betanecol & Hipersalivação \\
\hline Anticolinesterásicos & Fisiostigminina & \\
\hline & & \\
\hline
\end{tabular}

Fontes: Scully, 2003; Scully; Bagan-Sebastian, 2004.

\section{REFERÊNCIAS BIBLIOGRÁFICAS}

ANDRETTA, M.; TREGNAGHI, A.; PROSENIKLIEV, V.; STAFFIERI, A. Current opinions in sialolithiasis diagnosis and treatment.Acta Otorhinolaryngol Ital. 25: 145-149, 2005.

ARRESE, M.; TRAUNER, M. Molecular aspects of bile formation and cholestasis. Trends Mol. Med. 9: 558-564.

BANKS, M. R.; FARTHING, M. J. Fluid and electrolyte transport in the small intestine. Curr. Opin. Gastroenterol. 18(2): 176-181, 2002.

BERTOLOTTI, M.; GABBI, C.; ANZIVINO, C.; CRESTANI, M.; MITRO, N.; ET AL. Age-related changes in bile acid synthesis and hepatic nuclear receptor expression. Eur. J. Clin. Invest. 37: 501-508, 2007. 
BRITES, D.; TIRIBELLI, C. Metabolismo das bilirrubinas. Mecanismos celulares da secreção biliar. Patogenia da icterícia e da colestase. In: GAYOTTO, L. C.; AVANCINI, V. (eds.). Doenças do Fígado e das Vias Biliares. São Paulo: Atheneu, 2001.

BUTCHER, G. P. Jaundice and Liver Disease. In: Gastroenterology. Churchill Livingstone, 2003.

CATAlÁN, M. A.; NAKAMOTO, T.; MELVIN, J. E. The salivary gland fluid secretion mechanism. The Journal of Medical Investigation. 56: 192-196, 2009.

CHANDRA, R.; LIDDLE, R. A. Neural and hormonal regulation of pancreatic secretion. Curr. Opin. Gastroenterol. 25(5): 441-446, 2009.

CHANDRA, R.; LIDDLE, R. A. Recent advances in the regulation of pancreatic secretion. Curr. Opin. Gastroenterol. 30(5): 490-494, 2014.

CHIANG, J. Y. L. Bile acids: regulation of synthesis. J. Lipid. Res. 50(10): 19551966, 2009.

CHOI, S. Y.; LI, J.; JO, S. H.; LEE, S. J.; OH, S. B.; KIM J. S.; LEE, J. H.; PARK, K. Desipramine inhibits $\mathrm{Na}+/ \mathrm{H}+$ exchanger in human submandibular cells. J. Dent. Res. 85(9): 839-843, 2006.

CHOI, E.; ROLAND, J. T.; BARLOW, B. J.; O’NEAL, R.; RICH, A. E.; NAM, K. T.; SHI, C.; GOLDENRING, J. R. Cell lineage distribution atlas of the human stomach reveals heterogeneous gland populations in the gastric antrus. Gut. 63(11): 1711-1720, 2014.

CHOWDHURY-R, N.; LU, Y.; CHOWDHURY-R, J. Functions of the liver. In: RODÉS, J.; BENHAMOU, J. P.; BIEL, A.; REICHEN, J.; RIZZETTO, M. Textbook of hepatology. Principles from Basic Science to Clinical Practice. Blackwell Publishing, 2007.

CHU, S.; SCUBERT, M. L. Gastric secretion. Curr. Opin. Gastroenterol. 28(6): 587-593, 2012.

CIANCIO, S. G. Medication's impact on oral health. J. Am. Dent. Assoc. 135(10): 1440-1448, 2004.

CLOUSE, R. E.; DIAMANT, N. E. Motor Function of the Esophagus. In: Physiology of the Gastrointestinal Tract. Elsevier, 2006. 
CORREA, P. R. A. V.; NATHANSON M. H. Functions of the liver. In: RODÉS J; BENHAMOU J-P; BIEL A; REICHEN J; RIZZETTO M. Textbook of hepatology. Principles from Basic Science to Clinical Practice. Blackwell Publishing, 2007.

COSTA PINHO, A.; PINTO-DE-SOUSA, J.; BAPTISTA, M. ET AL. Brunner's gland hyperplasia: na usual cause of hemorragic shock. J. Surg. Case Rep. 2011: 1-2, 2011.

CROOG, S. H.; ELIAS, M. F.; COLTON, T.; BAUME, R. M.; LEIBLUM, S. R. Effects of Antihypertensive Medications on Quality of Life in Elderly Hypertensive Women. American Journal of Hypertension. 7(4): 329-339, 1994.

DODDSA, M. W. J.; JOHNSONB, D. A.; CHIH-KO, Y. Health benefits of saliva: a review. Journal of Dentistry. 33: 223-233, 2005.

DING, X. K.; HAKANSON, R. Evaluation of the specificity and potency of a series of cholecystokinin-B/gastrin receptor antagonists in vivo. Pharmacol. Toxicol. 79(3): 124-130, 1996.

FREEMAN, H. J.; THOMSON, A. B. R.The Small Intestine. In: THOMSON, A. B. R.; SCHAFFER, E. A. (eds.). First principles of gastroenteroly. JanssenOrtho, 2005.

FREUDENREICH, O. Review Drug-induced sialorrhea. 41(6): 411-418, 2005.

FRY, C. Secretions of the salivary glands and stomach. Surgery. 27(12): 503-506, 2009.

GAVAGHAN, M. Anatomy and Physiology of the Esophagus. AORN Journal. 69(2), 1999.

GORSKY,M.; EPSTEIN, J.B.; PARRY,J.; EPSTEIN, M.S.; LE, N.D.; SILVERMAN, S. The efficacy of pilocarpine and bethanechol upon saliva production in cancer patients with hyposalivation following radiation therapy. Oral Surg. Oral Med. Oral Pathol. Oral Radiol. Endod. 97(2): 190-195, 2004.

GUYTON, A. C.; HALL, J. E. Funções secretoras do trato alimentar. In: Tratado de Fisiologia Médica. Elsevier, 2011.

HATTORI, T.; WANG, P. L. Calcium antagonists cause dry mouth by inhibiting resting saliva secretion. Life Schi. 81(8): 683-90, 2007. 
HOU, W.; SCUBERT, M. L. Gastric secretion. Curr. Opin. Gastroenterol. 22(6): 593-598, 2006.

HYLEMON, P. B.; ZHOU, H.; PANDAK, W. M.; REN, S.; GIL, G.; DENT, P. Bile acids as regulatory molecules. J. Lipid. Res. 50: 1509-1520, 2009.

ISHIGURO, H.; YAMAMOTO, A.; NAKAKUKI, M.; YI, L.; ISHIGURO, M.; YAMAGUCHI, M.; KONDO, S.; MOCHIMARU, Y. Physiology and pathophysiology of bicarbonate secretion by pancreatic duct epithelium. Nagoya J. Med. Sci. 74(1-2): 1-18, 2012.

JOHANSSON, M. E. V.; AMBORT, D.; PELASEYED, T. eT AL. Composition and function role of the mucus layers in the intestine. Cellular and Molecular Life Sciences. 68: 3635-3641, 2011.

JOHANSSON, M. E. V.; SJÖVALL, H.; HANSON, G. C. The gastrointestinal mucus system in health and disease. Nat. Rev. Gastroenterol. Hepatol. 10(6): 352-361, 2013.

KAGNOFF, M. F.; ECKMANN, L. Epithelial cells as sensors for microbial infection. J. Clin. Invest. 100: 259-263, 1997.

KATZUNG, B. G.; MASTERS, S. B.; TREVOR, A. J. Farmacologia Básica e Clínica. 12 ed. Rio de Janeiro: McGraw-Hill, 2014

KIM, J. H.; PARK, S. H.; MOON, Y. W.; HWANG, S.; KIM, D.; ET AL. Histamine $\mathrm{H} 1$ receptor induces cytosolic calcium increase and aquaporin translocation in human salivary gland cells. J. Pharmacol. Exp. Ther. 330(2): 403-12, 2009.

KRALL, J. Bile acids, chaperones, and mammalian longevity. Rejuvenation Research. 15(2): 210-212, 2012.

KRAUSE, W. J. Brunner's glands: a structural, histochemical and pathological profile. Prog. Histochem. Cytochem. 35(4): 259-367, 2000.

KULLAK-UBLICK, G. A.; STIEGER, B.; MEIER P. J. Enterohepatic bile salt transporters in normal physiology and liver disease. Gastroenterology. 126(1): 322-342, 2004.

KUNTZ, E.; KUNTZ, H. D. Biochemistry and Functions of the Liver. In: Hepatology. Principles and Pratic. Springer, 2006b. 
. Biochemistry and Functions of the Liver. In: Hepatology. Principles and Pratic. Springer, 2006c.

. Morphology of the Liver. In: Hepatology. Principles and Pratic. Springer, 2006a.

KUROKI, R.; WEAVER, L. H.; MATTHEWS, B. W.A covalent enzyme-substrate intermediate with saccharide distortion in a mutant T4 lysozyme. Science. 262(5142): 2030-2033, 1993.

LAKRAJ, A. A.; MOGHIMI, N.; JABBARI, B. Sialorrhea: Anatomy, Pathophysiology and Treatment with Emphasis on the Role of Botulinum Toxins. Toxins. 5: 1010-1031, 2013.

LEE, M. G.; OHANA, E.; PARK, H. W.; YANG, D.; MUALLEM, S. Molecular mechanism of pancreatic and salivary gland fluid and HCO-3 secretion. Physiol. Rev. 92: 39-74, 2012.

LI, Q.; LUO, X.; ZENG, W.; MUALLEM, S. Cell-specific behavior of P2X7 receptors in mouse parotid acinar and duct cells. J. Biol. Chem. 278: 4755547561, 2003.

LIDDLE, R. A. Cholescystokinin cells. Annu. Rev. Physiol. 59: 221-242, 1997.

LIMA, D. P.; DINIZ, D. G.; MOIMAZ, S. A. S.; SUMIDA, D.H.; OKAMOTO, A. C. Saliva: reflection of the body. International Journal of Infectious Diseases. 14: 184-188, 2010.

LIU, H.; ZHEN, Q.; FARLEY, J. M. Antimuscarinic actions of antihistamines on the heart. Journal of Biomedical Science. 13(3): 395-401, 2006.

LONG, J. D.; ORLANDO, R. C. Esophageal Submucosal Glands: Structure and Function. The American Journal of Gastroenterology. 94(10): 2818-2824, 1999.

MALATHI, N.; MYTHILI, S; VASANTHI, H. R. Salivary Diagnostics: A Brief Review. ISRN Dentistry. 2014, Article ID 158786, 8 pages.

MATSUO, R.; GARRETT, J. R.; PROCTOR, G. B.; CARPENTER, G. H. Reflex secretion of proteins into submandibular saliva in conscious rats, before and after preganglionic sympathectomy. Journal of Physiology. 527: 175-184, 2000 . 
MAZZUCCHELLI, L.; MAUREEY, C. C. Anatomy. In: JOHNSON, L. R. Encyclopedia of Gastroenterology. Academic Press. 3 ed. 1: 408-412, 2003.

MESE, H.; MATSUO, R.Salivary secretion, taste and hyposalivation. Journal of Oral Rehabilitation. 34(10): 711-723, 2007.

MIRANDA-RIUS, J.; BRUNET-LLOBET, L.; LAHOR-SOLER, E.; FARRÉ, M. Salivary secretory disorders, inducing drugs, and clinical management. Int. Med. Sci. 12(10): 811-824, 2015.

MO, J. Z.; WANG, C. D. Effects of the gut hormones on gastricemptying. Biomedical Research-Tokyo. 15(2): 127-131, 1994.

NAKAMOTO, T.; BROWN, D. A.; CATALAN, M. A.; GONZALEZ-BEGNE, M.; ROMANENKO, V. G.; MELVIN, J. E. Purinergic P2X7 receptors mediate ATP-induced saliva secretion by the mouse submandibular gland. J. Biol. Chem. 285: 4815-4822, 2009.

NANCI, A. Ten Cate Histologia Oral: Desenvolvimento, Estrutura e Função. Elsevier, 2008.

NAPEÑAS, J. J.; BRENNAN, M. T.; FOX, P. C. Diagnosis and treatment of xerostomia (dry mouth). Odontology. 97: 76-83, 2009.

NEDERFORS, T.; NAUTOFTE, B.; TWETMAN, S. Effects of furosemide and bendroflumethiazide on saliva flow rate and composition. Arch. Oral. Biol. 49(7): 507-513, 2004.

OSTROW, J. D. Overview of bile pigment metabolism. In: OSTROW, J. D. (ed.). Bile pigments and jaundice: molecular, metabolic and medical aspects. New York: Marcel Dekker, 1986.

PATTI, M. G.; GANTERT, W.; WAY, L. W. Surgery of the esophagus: Anatomy and Physiology. Surgical Clinics of North America. 77(5): 959-970, 1997.

PLEUVRY, B. J. Gastric disorders: modifications of gastric content, antacids and drugs influencing gastric secretions and motility. Anesthesia and Intensive Care Medicine. 10(7): 351-354, 2009.

PRASANTHI, B.; KANNAN, N.; PATIL, R. Effects of Diuretics on Salivary Flow, Composition and Oral Health Status: A clinic-biochemical study. Ann. Med. Health Sci. Res. 4(4): 549-553, 2014. 
PROCTOR, G. B.; CARPENTER, G. H. Review: Regulation of salivary gland function by autonomic nerves. Autonomic Neuroscience. 133: 3-18, 2007.

RAGUNATH C.; MANUEL, S. G. A.; KASINATHAN, C.; RAMASUBBU, N. Structure-function relationships in human salivary $\alpha$-amylase role of aromatic residues in a secondary binding site. Biologia. 63: 1028-1034, 2008.

RANG, H. P.; DALE, M. M.; RITTER, J. M.; FLOWER, R.; HENDERSEN, G. Trato Gastrointestinal. In: Farmacologia. 7 ed. Rio de Janeiro: Elsevier, 2012.

RESHETNYAK, V. I. Physiological and molecular biochemical mechanisms of bile formation. World J. Gastroenterol. 19: 7341-7360, 2015.

RODRIGUES, S. S.; FONSECA, C. C.; NEVES, M. T. D. Células endócrinas do sistema gastroenteropancreático: Conceitos, distribuição, secreções, ação e controle. Arq. ciên. vet. zool. 8(2): 171-180, 2005

RUSSEL, D. W. The enzymes, regulation, and genetics of bile acids synthesis. Annu. Rev. Biochem. 72: 137-174, 2003.

SANNER, M. F. Python: a programming language for software integration and development. J. Mol. Graph. Model 17(1): 57-61, 1999.

SCREEBY, L. M.; SCHWARTZ, S. S. A reference guide to drugs and dry mouth 2nd edition. Gerodontology. 14(11): 33-47, 1997.

SCHUBERT, M. L. Gastric secretion. Curr. Opin. Gastroenterol, v. 16, n. 6, pp. 463-468, 2000.

. Gastric secretion. Curr. Opin. Gastroenterol. 17(6): 481-488, 2001.

. Gastric secretion. Curr. Opin. Gastroenterol. 18(6): 639-649, 2002.

. Gastric secretion. Curr. Opin. Gastroenterol. 20(6): 519-525, 2004.

. Gastric secretion. Curr. Opin. Gastroenterol. 21(6): 636-643, 2005.

. Gastric secretion. Curr. Opin. Gastroenterol. 23(6): 595-601, 2007.

. Gastric secretion. Curr. Opin. Gastroenterol. 26(6): 598-603, 2010.

. Gastric secretion. Curr. Opin. Gastroenterol. 27(6): 536-542, 2011. 
. Gastric secretion. Curr. Opin. Gastroenterol. 30(6): 578-582, 2014.

. Functional anatomy and physiology of gastric secretion. Curr. Opin. Gastroenterol. 31(6): 479-485, 2015.

SCULLY, C. B. E. Drug effects on salivary glands: dry mouth. Oral Diseases. 9: 165-176, 2003.

SCULLY, C.; BAGAN-SEBASTIAN, J. V. Adverse Drug Reactions in the Orofacial Region. Crit. Rev. Oral Biol. Med. 15(4): 221-240, 2004.

SILVA, S.; AZEVEDO, L. R.; LIMA, A. A.; IGNÁCIO, S. A.; MACHADO, M. A. ET $A L$. Effects of fluoxetine and venlafaxine and pilocarpine on rat parotid glands. Med. Chem. 5(5): 483-490, 2009.

SOM, P. M.; BRANDWEIN, M. S.Anatomy and pathology of the salivary glands. In: Anatomy and Pathology Head and Neck Imaging. Elsevier, 2003.

SONESSON, M.; ELIASSON, L.; MATSSON, L. Minor salivary gland secretion in children and adults.Archives of Oral Biology. 48(7): 535-539, 2003.

STURM, A.; SUDERMANN, T.; SCHULTE, K-M.; GOEBELL, H.; DIGNASS, A. U. Modulation of intestinal epithelial wound healing in vitro and in vivo by lysophosphatidic acid. Gastroenterol. 117: 368-377, 1999.

TANNA, A.; RADEMAKER, A.; STEWART W., FELDMAN, R. Meta-analysis of the efficacy and safety of alpha2-adrenergic agonists, beta-adrenergic antagonists, and topical carbonic anhydrase inhibitors with prostaglandin analogs. Arch. Ophthalmol.128: 825-833, 2010.

TRAUNER, M.; WAGNER, M.; FICKERT, P. ET AL. Molecular regulation of hepatobiliary transport systems: clinical implications for understanding and treating cholestasis. J. Clin. Gastroenterol. 39(4): 111-124, 2005.

TURNER J. T.; LANDON L. A.; GIBBONS S. J.; TALAMO B. R. Salivary gland P2 nucleotide receptors. Crit. Rev. Oral Biol. Med. 10: 210-224, 1999.

VARGA, G. Physiology of the salivary glands. Surgery (Oxford). 30(11): 578-583, 2012. 
VEERMAN, E. C. I.; VAN DEN KEIJBUS, P. A. M.; VISSINK, A.; VAN NIEUW AMERONGEN, A. Human glandular salivas: their separate collection and analysis. Eur. J. Oral Sci. 104: 346-352, 1996.

VINAYAK, V.; RAJESHWARI, G. A.; HASHIKESH, A.P.; MITTAL, S. Adverse effects of drugs on saliva and salivary glands. Journal of Oral Sciences. 5(1): 15-20, 2013.

WAGNER, D.; SPAHN-LANGGUTH, H.; HANAFY, A.; KOGGEL, A.; LANGGUTH, P. Intestinal drug efflux: formulation and food effects. Advanced Drug Delivery Reviews. 50: 13-31, 2001.

WALPNIR, R. A.; TEICHBERG, S. Regulation mechanisms of intestinal secretion: implications in nutrient absorption. Nutr. Biochem. 13(4): 190-199, 2002.

WILLIAM, C. Y.; TA-MIN, C. Secretin, 100 years later. J. Gastroenterol. 38: 1025-1035, 2003.

WORRELL R. T.; CUPPOLETTI, J. E.; MATTHEWS, J. B. Colonic Absorption and Secretion. In: JOHNSON, L. R. Encyclopedia of Gastroenterology.3 ed. Academic Press, 2003.

YASUDA, S. U.; YASUDA, R. P. Affinities of brompheniramine, chlorpheniramine, and terfenadine at the five human muscarinic cloninergic receptor subtypes. Pharmacoterapy. 19(4): 447-451, 1999.

YASUTADA, A.; JONATHAN, D. K. Duodenal Chemosensing and Mucosal Defenses. Digestion. 83: 25-31, 2011.

YNAI-INAMURA, H.; OHTAKE, A.; NOGUCHI, Y.; HATANAKA, T.; SUZUKI, M.; UESHIMA, K.; SATO, S.; SASAMATA, M. Effects of $\alpha 1$-adrenoceptor antagonists on phenylephrine-induced salivar secretion and intraurethral pressure elevation in anesthetized rats. Eur. J. Pharmacol. 679(1-3): 127-131, 2012.

YOKOYAMA, Y; NAGINO, M; NIMURA, Y. Mechanisms of hepatic regeneration following portal vein embolization and partial hepatectomy: a review. World J. Suger. 31: 367-374, 2007. 
